Prepared in cooperation with the Bureau of Ocean Energy Management and the U.S. Fish and Wildlife Service Kaua'i National Wildlife Refuge Complex

\title{
Population Estimates for Selected Breeding Seabirds at Kīlauea Point National Wildlife Refuge, Kaua'i, in 2019
}

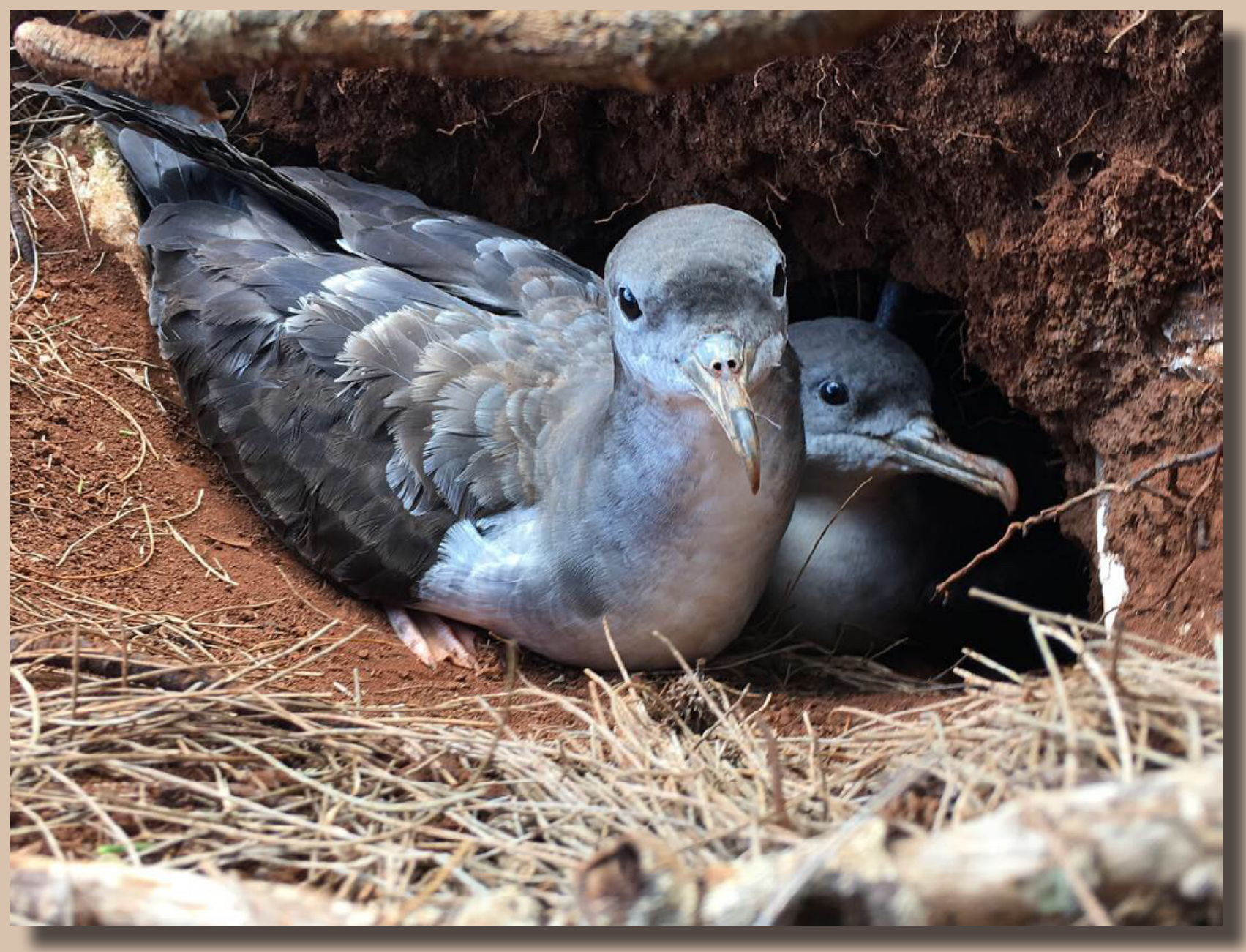

Data Series 1130

U.S. Department of the Interior

U.S. Geological Survey 
Cover Photo: A pair of wedge-tailed shearwaters (Ardenna pacifica) sit in front of a nesting burrow, Kīlauea Point National Wildlife Refuge, Kaua'i. Photograph taken by Jonathan Felis, U.S. Geological Survey, July 1, 2019. 


\section{Population Estimates for Selected Breeding Seabirds at Kīlauea Point National Wildlife Refuge, Kaua'i, in 2019}

By Jonathan J. Felis, Emily C. Kelsey, Josh Adams, Jennilyn G. Stenske, and Laney M. White

Prepared in cooperation with the Bureau of Ocean Energy Management and the U.S. Fish and Wildlife Service Kaua'i National Wildlife Refuge Complex

Data Series 1130 


\title{
U.S. Department of the Interior \\ DAVID BERNHARDT, Secretary
}

\author{
U.S. Geological Survey \\ James F. Reilly II, Director
}

U.S. Geological Survey, Reston, Virginia: 2020

For more information on the USGS - the Federal source for science about the Earth, its natural and living resources, natural hazards, and the environment-visit https://www.usgs.gov or call 1-888-ASK-USGS.

For an overview of USGS information products, including maps, imagery, and publications, visit https://store.usgs.gov/.

Any use of trade, firm, or product names is for descriptive purposes only and does not imply endorsement by the U.S. Government.

Although this information product, for the most part, is in the public domain, it also may contain copyrighted materials as noted in the text. Permission to reproduce copyrighted items must be secured from the copyright owner.

Suggested citation:

Felis, J.J., Kelsey, E.C., Adams, J., Stenske, J.G., and White, L.M., 2020, Population estimates for selected breeding seabirds at Kīlauea Point National Wildlife Refuge, Kaua'i, in 2019: U.S. Geological Survey Data Series 1130, 32 p., https://doi.org/10.3133/ds1130.

Associated data for this publication:

Felis, J.J., Kelsey, E.C., Adams, J., Stenske, J.G., and White, L.M., 2020, Population estimates for selected breeding seabirds at Kīlauea Point National Wildlife Refuge, Kaua'i, in 2019: U.S. Geological Survey data release, https://doi.org/10.5066/P93MPDR1.

ISSN 2327-638X (online) 


\section{Acknowledgments}

The staff at Kaua'i National Wildlife Refuge Complex (U.S. Fish and Wildlife Service) provided land access, support, and expertise, without which this work would not have been possible. Heather Abbey Tonneson, Kim Uyehara, and Daniel Dewey (U.S. Fish and Wildlife Service) were instrumental in facilitating this project and provided historical survey data. Brenda Zaun (U.S. Fish and Wildlife Service) offered invaluable feedback and knowledge of past seabird survey work at Kīlauea Point National Wildlife Refuge. Julie Yee (U.S. Geological Survey) provided support on statistical methods. Eric VanderWerf (Pacific Rim Conservation), Jenni Learned (Maui Nui Seabird Recovery Project), and Dave Pereksta (Bureau of Ocean Energy Management) provided insightful reviews of this manuscript. The Hawai'i State Department of Land and Natural Resources, Division of Forestry and Wildlife (Sheri Mann, Thomas Ka'iakapu, and Jason Omick) provided assistance with permitting and authorized this work under the State of Hawai'i Protected Wildlife Permit Number WL19-35. Work also was authorized under Kīlauea Point National Wildlife Refuge Research and Monitoring Special Use Permit Number 12530-19-054. This study was funded in part by the U.S. Department of the Interior, Bureau of Ocean Energy Management, Environmental Studies Program, Washington D.C., through Intra-agency Agreement No. M17PG00038 with the U.S. Geological Survey, Western Ecological Research Center. This report has been technically reviewed by the Bureau of Ocean Energy Management, and it has been approved for publication. 



\section{Contents}

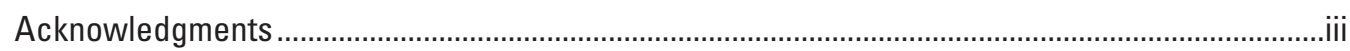

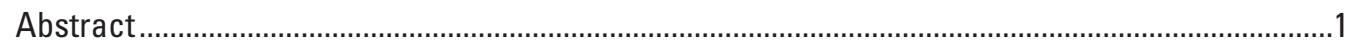

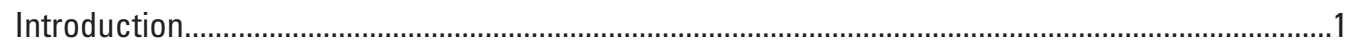

Red-tailed Tropicbird and White-tailed Tropicbird ......................................................................

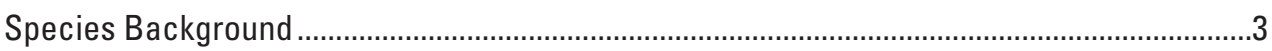

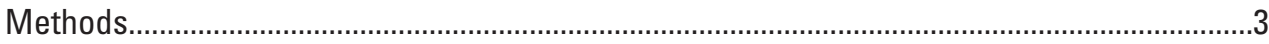

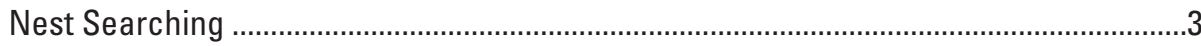

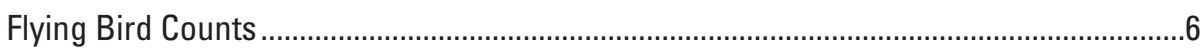

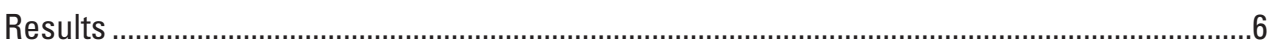

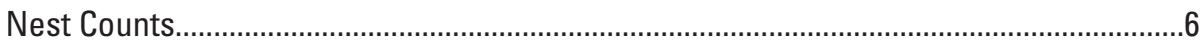

Phenology and Reproductive Success ......................................................................

Tropicbird Flying Bird Counts..........................................................................................11

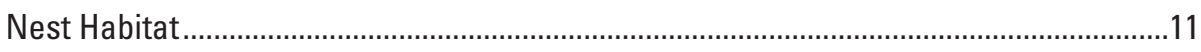

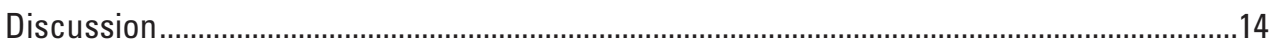

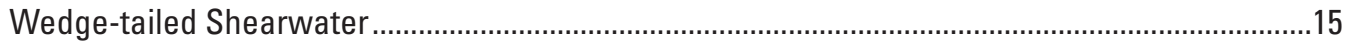

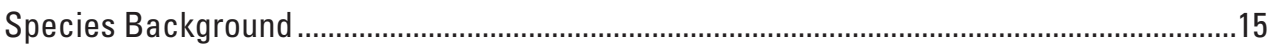

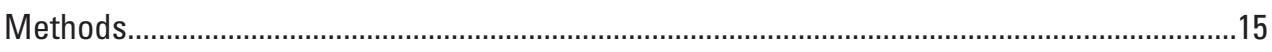

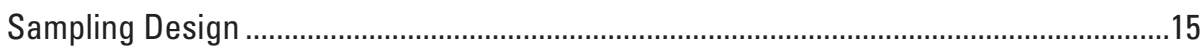

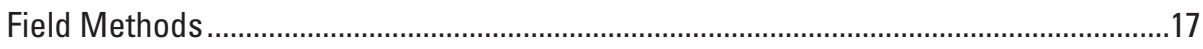

Nest Site Abundance and Occupancy Estimation ........................................................17

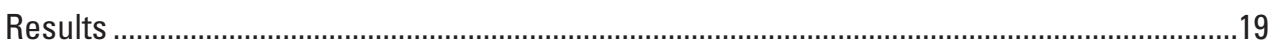

Field Sampling Effort .............................................................................................19

Nest Site Abundance and Occupancy Estimation ........................................................19

Nesting Habitat Characteristics ..............................................................................19

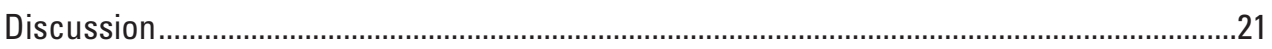

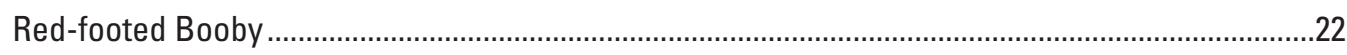

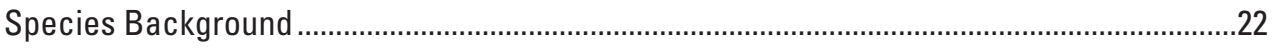

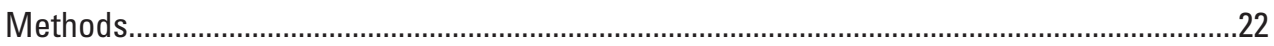

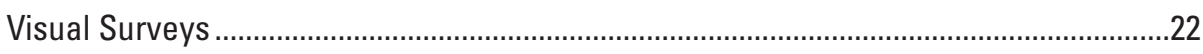

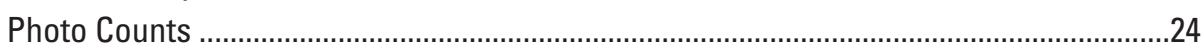

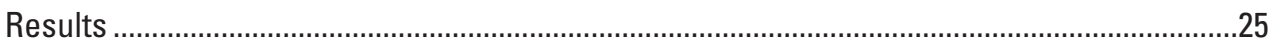

Visual Counts and Historical Comparison.................................................................25

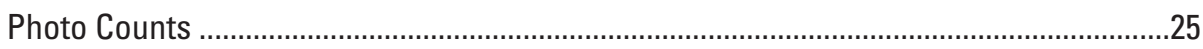

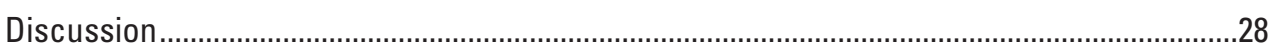

Summary

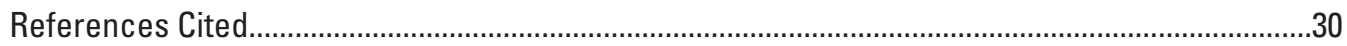

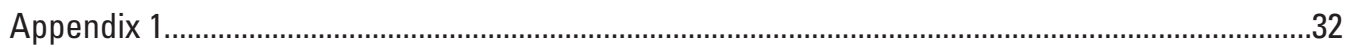




\section{Figures}

1. Map of main Hawaiian Islands and location of Kīlauea Point National Wildlife Refuge on the north shore of Kaua'i.

2. Map of Kīlauea Point National Wildlife Refuge showing search effort for red-tailed and white-tailed tropicbirds.

3. Map of Kīlauea Point National Wildlife Refuge showing red-tailed and white-tailed active and potential nest sites discovered during April 8-11, May 13-18, and July 1-7, 2019

4. Graph showing current and historical nest counts for red-tailed tropicbirds at Kīlauea Point National Wildlife Refuge, Kaua'i .

5. Bar charts depicting counts of flying red-tailed and white-tailed tropicbirds observed from Mōkōlea Point, Crater Hill, and Kīlauea Point on May 15, 2019, at Kīlauea Point National Wildlife Refuge, Kaua'i

6. Histograms of the proportion of different habitat structures, landforms around the nest, and dominant vegetation types at red-tailed tropicbird nests at Kīlauea Point National Wildlife Refuge, Kaua'i, in 2019

7. Map of strata used to sample and estimate wedge-tailed shearwater abundance in Kīlauea Point National Wildlife Refuge, Kaua'i.....

8. Box-and-whisker plots of wedge-tailed shearwater nest site density by coverage estimation categories within habitat cover types measured in sampling plots across Kīlauea Point National Wildlife Refuge, Kaua'i, in July 2019 ......20

9. Map of Kīlauea Point National Wildlife Refuge, Kaua'i, showing red-footed booby sub-colony areas.

10. Images showing interface of DotDotGoose and examples of nesting, roosting, or unknown red-footed booby images

11. Graph showing summary of visual counts of red-footed boobies at Kilauea Point National Wildlife Refuge, Kaua'i, through time using historical viewpoints, broken up by subcolony.

\section{Tables}

1. Habitat classification used to describe tropicbird nests

2. Summary of unique red-tailed tropicbird nests found in Kīlauea Point National Wildlife Refuge, Kaua'i, April 8-11, May 13-18, July 1-7, and overall, in 2019

3. Summary of nest status for all unique red-tailed tropicbird nests found in different areas of Kīlauea Point National Wildlife Refuge, Kaua'i, April 8-11, May 13-18, and July 1-7, 2019.

4. Current and historical active nest counts for red-tailed tropicbird at Kīlauea Point National Wildlife Refuge, Kaua'i

5. Breakdown of tropicbird chick feathering stages used to estimate chick age in nest checks at Kīlauea Point National Wildlife Refuge and the resulting chick stages identified in the April, May, and July 2019 checks 
6. Red-tailed tropicbird phenology measured during 2003-08 at Kīlauea Point National Wildlife Refuge, Kaua'i

7. Monthly distribution of red-tailed tropicbird hatching across breeding seasons at Kīlauea Point National Wildlife Refuge, Kaua'i, 2003-05.

8. Red-tailed tropicbird reproductive success measured during 2003-07 and minimum reproductive failure as measured in 2019 at Kīlauea Point National Wildlife Refuge, Kaua'i.

9. Counts of flying red-tailed and white-tailed tropicbirds observed from Mōkōlea Point, Crater Hill, and Kīlauea Point on May 15, 2019, at Kīlauea Point National Wildlife Refuge, Kaua'i.

10. Summary of stratum-specific sampling effort and abundance estimation results for wedge-tailed shearwater nest sites in Kīlauea Point National Wildlife Refuge, Kaua'i, July 1-7, 2019.

11. Visual and photographic red-footed booby survey results from May 2019 at Kīlauea Point National Wildlife Refuge, Kaua'i

12. Current and historical visual nest counts for red-footed boobies at Kīlauea Point National Wildlife Refuge, Kaua'i

13. Recount results of red-footed boobies from ground photographs taken in May 2019 at the Crater Hill West sub-colony, Kīlauea Point National Wildlife Refuge, Kaua'i

\section{Conversion Factors}

International System of Units to U.S. customary units

\begin{tabular}{lcl}
\hline \multicolumn{1}{c}{ Multiply } & By & \multicolumn{1}{c}{ To obtain } \\
\hline & Length & \\
\hline meter $(\mathrm{m})$ & 3.281 & foot $(\mathrm{ft})$ \\
kilometer $(\mathrm{km})$ & 0.6214 & mile $(\mathrm{mi})$ \\
millimeter $(\mathrm{mm})$ & 0.03937 & inch $(\mathrm{in})$. \\
centimeter $(\mathrm{cm})$ & 0.3937 & inch $(\mathrm{in})$. \\
meter $(\mathrm{m})$ & 1.094 & yard $(\mathrm{yd})$ \\
\hline & Area & \\
\hline square kilometer $\left(\mathrm{km}^{2}\right)$ & 0.3861 & square mile $\left(\mathrm{mi}^{2}\right)$ \\
square kilometer $\left(\mathrm{km}^{2}\right)$ & 247.105 & acre \\
square meter $\left(\mathrm{m}^{2}\right)$ & 10.764 & square foot $\left(\mathrm{ft}^{2}\right)$ \\
\hline
\end{tabular}

\section{Datum}

Horizontal coordinate information is referenced to the World Geodetic System of 1984 (WGS 84). 


\section{Abbreviations}

$\begin{array}{ll}\text { GPS } & \text { Global Positioning System } \\ \text { IUCN } & \text { International Union for Conservation of Nature } \\ \text { MHI } & \text { Main Hawaiian Islands } \\ \text { KPNWR } & \text { Kīlauea Point National Wildlife Refuge } \\ \text { USGS } & \text { U.S. Geological Survey }\end{array}$




\title{
Population Estimates for Selected Breeding Seabirds at Kīlauea Point National Wildlife Refuge, Kaua'i, in 2019
}

\author{
By Jonathan J. Felis, Emily C. Kelsey, Josh Adams, Jennilyn G. Stenske, and Laney M. White
}

Abstract

Kîlauea Point National Wildlife Refuge (KPNWR) is an important seabird breeding site located at the northeastern tip of Kaua' $i$ in the main Hawaiian Islands. Despite the regional significance of KPNWR as one of the most important breeding sites for red-tailed tropicbirds (Phaethon rubricauda), red-footed boobies (Sula sula), and wedge-tailed shearwaters (Ardenna pacifica) in the main Hawaiian Islands, robust and accurate population surveys have not been consistently conducted and recent information is lacking. In this study, we completed comprehensive population surveys for these three species during the 2019 breeding season. Using direct censusing methods (ground-searching, visual and photographic counts), we determined that 387 red-tailed tropicbird and 5,049 red-footed booby breeding pairs nested at KPNWR in 2019. Additionally, we performed surveys of aerially displaying tropicbirds to estimate a potential population of 30 white-tailed tropicbird (Phaethon lepturus) breeding pairs at KPNWR. Using a stratified-random plot-sampling method, we estimated that 20,998 wedge-tailed shearwater pairs nested at KPNWR in 2019. The breeding population size results in this study are greater than those reported in the past for KPNWR. We suggest that the red-tailed tropicbird breeding population has increased since the mid-2000s (when population estimates were last made), whereas red-footed booby numbers likely have remained similar and 2019 results show an increase from past estimates because of the more comprehensive methods used in this study. The results of these surveys provide current and accurate population sizes for these species that can serve as (1) benchmarks for future management and monitoring at KPNWR and (2) important components of population-level assessments of seabird vulnerability to potential offshore wind energy development in the main Hawaiian Islands.

\section{Introduction}

Kîlauea Point National Wildlife Refuge (KPNWR) is located at the northeastern tip of Kaua' $i$ in the main Hawaiian Islands (MHI; fig. 1). The 199-acre refuge supports an abundant and diverse population of breeding seabird species, including the red-tailed tropicbird (Phaethon rubricauda, Koa'e ula), white-tailed tropicbird (P. lepturus, Koa'e kea), wedge-tailed shearwater (Ardenna pacifica, 'Ua'u kani), Newell's shearwater (Puffinus newelli, 'A'o), Laysan albatross (Phoebastria immutabilis, Mōlī), and red-footed booby (Sula sula, 'ā; U.S. Fish and Wildlife Service, 2016). Additional non-breeding seabird species known to frequent KPNWR include the great frigatebird (Fregata minor, 'iwa) and brown booby (Sula leucogaster, ' $\bar{a}$ ), whereas black-footed albatross (Phoebastria nigripes, ka'upu) and Kermadec petrel (Pterodroma neglecta) are infrequent visitors. The elevated sea cliffs at KPNWR are less vulnerable to rising seas and increased storm surges than most of the nesting habitat for these species in the northwestern Hawaiian Islands (U.S. Fish and Wildlife Service, 2016). As the climate changes and sea levels rise, remaining high-island nesting habitat at KPNWR could become increasingly more important for these seabird species (Hatfield and others, 2012; Reynolds and others, 2015). To combat climate change and achieve 100-percent clean energy dependence by 2045, the State of Hawai' $i$ has developed an energy initiative which includes offshore wind energy development (State of Hawaii, 2020). The potential effects on seabirds from offshore development is of management and conservation concern (Bureau of Ocean Energy Management, 2020). With expected changes in seabird habitats because of climate change and the possibility for additional external pressures brought on by offshore wind energy development, it is imperative to understand the current population sizes of breeding seabirds at important seabird nesting sites like KPNWR. 


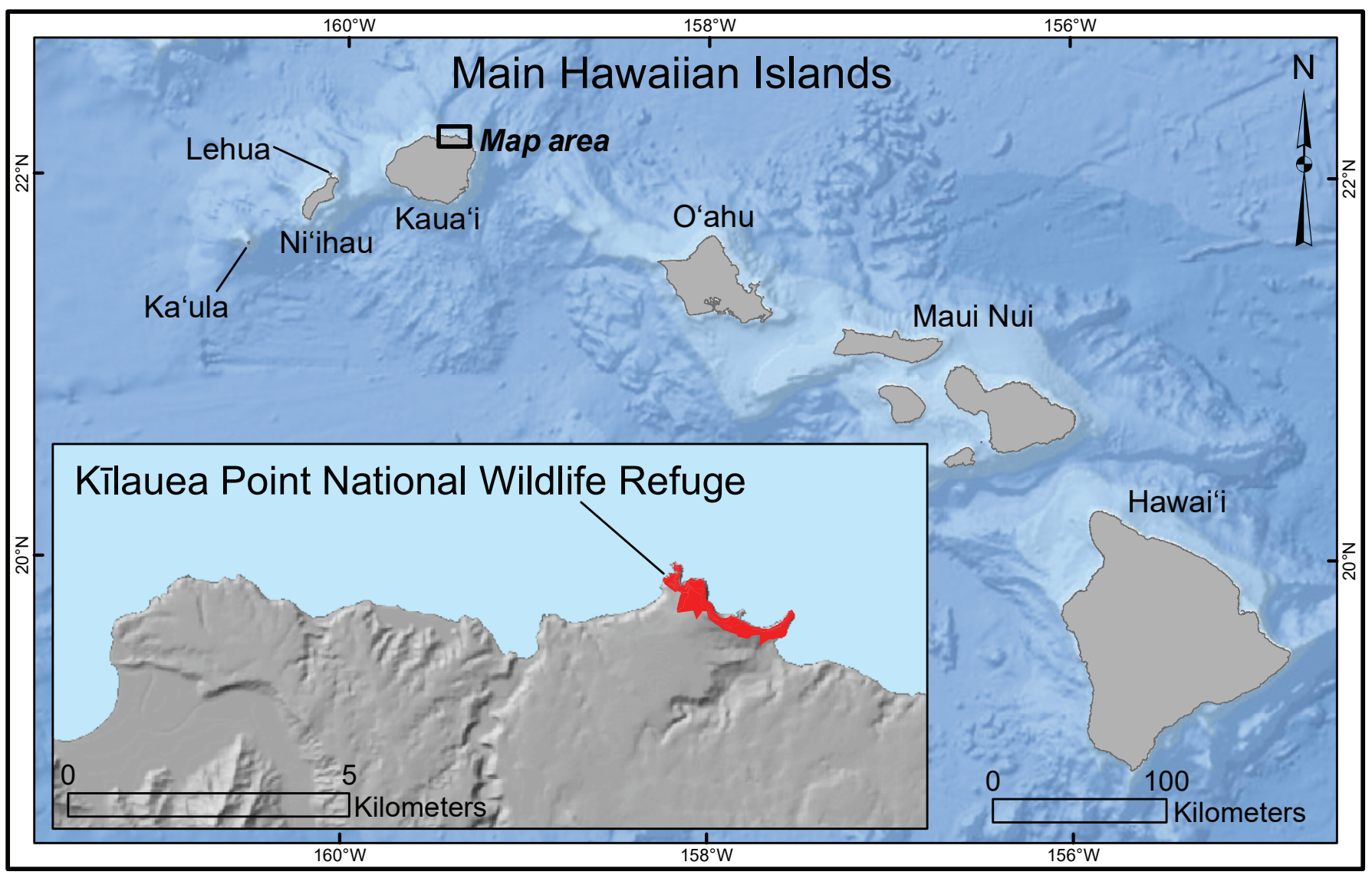

Figure 1. Main Hawaiian Islands and location of Kīlauea Point National Wildlife Refuge on the north shore of Kaua'i.

Existing refuge-wide monitoring programs at KPNWR focus on Newell's shearwater and Laysan albatross (U.S. Fish and Wildlife Service, 2016). In addition, the Nihoku Ecosystem Restoration Project, a partnership among multiple government and non-profit groups, provides active management and monitoring of translocated Newell's shearwaters and Hawaiian petrels (Pterodroma sandwichensis, ' $\mathrm{Ua}$ 'u) within a predator exclusion fence at KPNWR (Young and others, 2018). Despite the regional significance of KPNWR as one of the most important breeding sites for red-tailed tropicbirds, red-footed boobies, and wedge-tailed shearwaters throughout the MHI, robust and accurate population estimates for these species have not been consistently made (U.S. Fish and Wildlife Service, 2016; Pyle and Pyle, 2017). In this study, we completed population surveys for red- and white-tailed tropicbirds, red-footed boobies, and wedge-tailed shearwaters during the 2019 breeding season. The results of these surveys provide updated population sizes for these species at KPNWR and serve as a reference point for future monitoring. The data reported herein can be accessed in an associated data release (Felis and others, 2020). 


\section{Red-tailed Tropicbird and White-tailed Tropicbird}

\section{Species Background}

The red-tailed tropicbird (International Union for Conservation of Nature [IUCN] "Least Concern"; International Union for Conservation of Nature, 2020) ranges across tropical and sub-tropical areas of the Pacific and Indian oceans. Of the estimated 30,000-40,000 breeding pairs worldwide (Schreiber and Schreiber, 2020), approximately 9,000-12,000 pairs breed in Hawai' $i$, primarily at sites throughout the northwestern Hawaiian Islands (Harrison, 1990; Pyle and Pyle, 2017). The MHI breeding population has been estimated at 1,035 pairs with most on Ka'ula, Lehua, Kaua'i, and O'ahu; breeding also has been documented in lesser numbers on Ni'ihau, Maui Nui, and Hawai' $\mathrm{i}$ (VanderWerf and others, 2014; Pyle and Pyle, 2017). In the MHI, red-tailed tropicbirds are annual, asynchronous breeders present at coastal nesting sites and surrounding waters predominantly during the breeding season (January-October; Harrison, 1990; VanderWerf and others, 2007; VanderWerf and Young, 2014). Females lay a single egg on the ground where adequate shade exists, such as under vegetation on any slope or in natural alcoves, caves, and crevices on rocky slopes and cliffs. Incubation exchanges and chick feedings exclusively are during daylight (Harrison, 1990; Tyler, 1991; VanderWerf and others, 2007; Adams and others, 2020; Schreiber and Schreiber, 2020). Nesting in the MHI is restricted to steep coastal bluffs, shorelines, and cliffs, within predator proof enclosures, and on offshore islets where non-native predators are in low abundance or are absent (VanderWerf and Young, 2014).

The largest aggregation of red-tailed tropicbirds on Kaua' $i$ is located at KPNWR (Pyle and Pyle, 2017). Biologists at KPNWR counted red-tailed tropicbird nests, monitored reproductive success, and banded individual birds from 2003 to 2008 (U.S. Fish and Wildlife Service, unpub. data, 2019; summarized in this study for comparison), but no comprehensive surveys have happened since. Annual population counts from this time period ranged from 135 to 231 breeding pairs (U.S. Fish and Wildlife Service, 2016).

White-tailed tropicbirds (IUCN "Least Concern"; International Union for Conservation of Nature, 2020) are pan-tropical and are found on oceanic islands across the Pacific, Indian, and Atlantic Oceans. White-tailed tropicbirds commonly use natural rock crevices, tunnels, or alcoves for nesting and often occupy sites that are too small for the relatively larger red-tailed tropicbird (Lee and Walsh-McGee, 2020). Nest sites in MHI can be found much farther inland than those of red-tailed tropicbirds and are often on remote cliff faces, making them less susceptible to predation (Lee and Walsh-McGee, 2020). The global population estimate is less than 200,000 pairs, but is considered imprecise because of remote, dispersed, and inaccessible nesting habitat (Lee and Walsh-McGee, 2020). The population in Hawai' $i$ is estimated to be 1,550 breeding pairs, mostly distributed throughout the MHI where suitable cliff habitat exists for nesting (Pyle and Pyle, 2017). They can be observed at KPNWR year-round with peak nesting occurring from March to October, although it is asynchronous (U.S. Fish and Wildlife Service, 2016). Because of the inaccessibility of their nesting habitat, only four white-tailed tropicbirds nests have been previously monitored (U.S. Fish and Wildlife Service, unpub. data, 2019) and no breeding population estimate exists for KPNWR.

\section{Methods}

\section{Nest Searching}

During April 8-11, May 13-18, and July 1-7, 2019, we censused red- and white-tailed tropicbird nests in KPNWR by searching all foot-accessible areas and by searching all cliffs and islets with spotting scopes from remote vantage points. We censused over the course of three visits to account for prolonged and asynchronous nesting (VanderWerf and Young, 2014; Schreiber and Schreiber, 2020). For groundsearching, we used previous nest census results (U.S. Fish and Wildlife Service, unpub. data, 2019), recommendations from the previous Refuge biologist (B. Zaun, oral commun., 2019), and our knowledge of tropicbird nesting habitat, to focus searches in areas where nesting was likely: along cliff edges and steep slopes, particularly at the base of ironwood trees (Casuarina equisetifolia) and beneath dense shrubs. Within these habitats, we searched the ground as thoroughly as vegetation and topography would permit. In areas that we did not expect to be suitable tropicbird nesting habitat (for example, flat, open areas far from cliff edges or windward slopes), we scanned the area but did not search as thoroughly as in suspected nesting habitat. See figure 2 for Global Positioning System (GPS) tracklines of ground-searching effort and locations used as vantages for remote viewing (see appendix table 1.1 for specific locations of remote viewing vantages). 


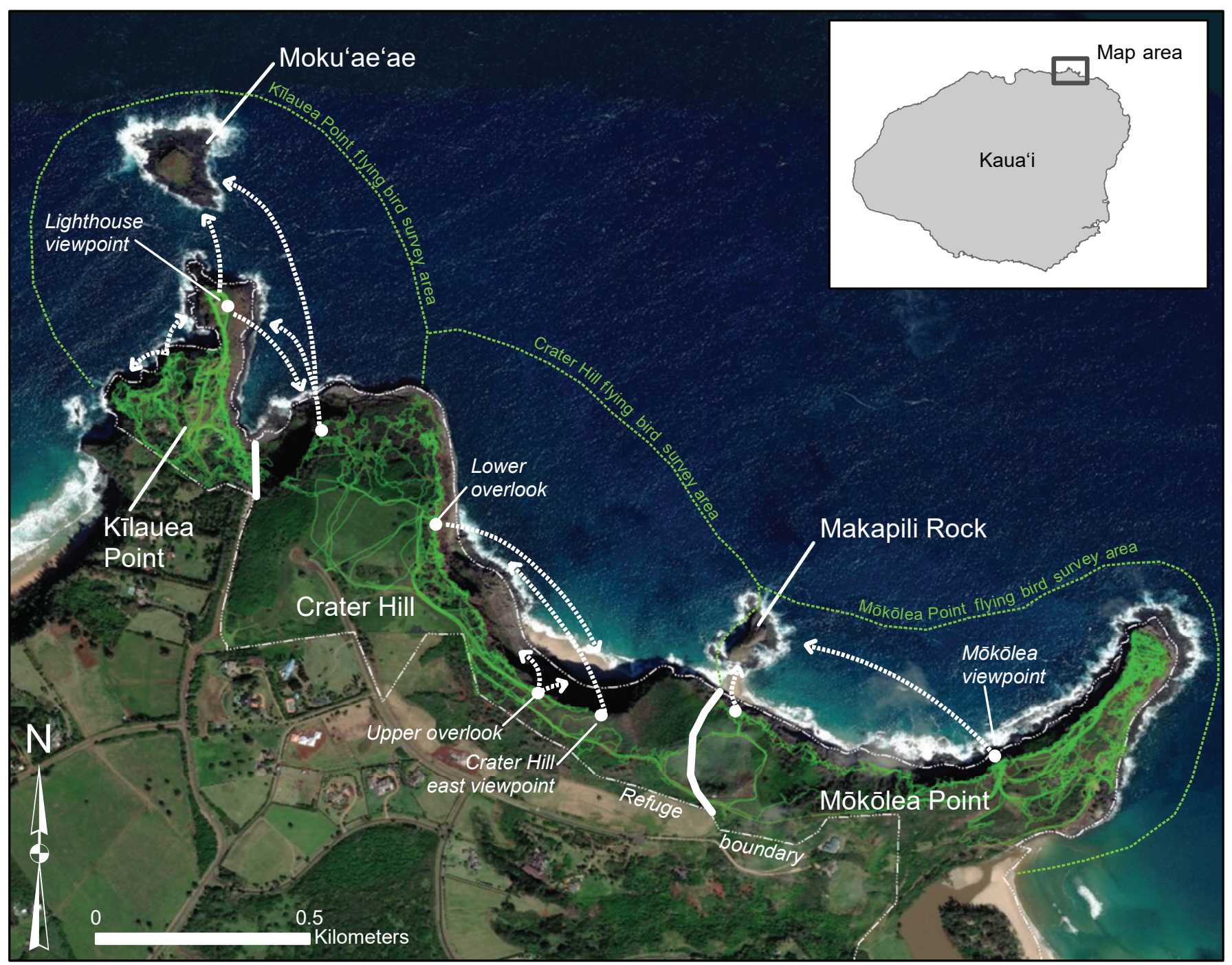

Figure 2. Kīlauea Point National Wildlife Refuge (KPNWR) showing search effort for red-tailed (Phaethon rubricauda) and white-tailed (P. lepturus) tropicbirds. Solid white lines indicate subdivisions of refuge used for summarizing nest counts (Kīlauea Point, Crater Hill, and Mōkōlea Point). Overlooks and viewpoints referenced in the text are labeled. White dashed arrows indicate vantages used to remotely view tropicbirds nesting on cliffs and islets. Partially transparent green lines in background are Global Positioning System tracklines of ground search effort for tropicbird nests in April, May, and July 2019. Dashed green lines show areas of the colony in which flying/displaying tropicbirds were counted. Makapili Rock and Moku’ae'ae Islet are managed by the state of Hawaii and are not part of KPNWR. 
For ground-accessible nests, we assigned a nest number, recorded the GPS location, flagged the nest, and recorded nest contents and habitat type. For inaccessible nest habitat, we used a spotting scope to view remote cliffs and offshore islets (Makapili and Moku'ae'ae) for tropicbird nests. For remote sites, we identified tropicbirds to species, recorded the location using a georeferenced satellite image, collected reference photographs for subsequent checks, and recorded habitat type. In May and July 2019, we used locations of nests from previous visits (and reference photographs for remotely viewed sites) to record tropicbird presence at previously identified nest sites and also to assist with searches for newly initiated nests. In July, our last visit, we removed flags after checking previously located nests and recorded, but did not flag, newly initiated nests. We defined active nests as sites where it was possible to confirm that an adult was incubating an egg or brooding a chick or where an unattended chick was present. Potential nests included sites where an adult was occupying a suitable nest site, but no egg or chick was present, and where nest contents were unknown (usually remotely viewed cliff nests). Following previous KPNWR survey methods (U.S. Fish and Wildlife Service, unpub. data, 2019), we also defined remotely viewed nests as active if an adult was present for two consecutive visits. We classified nest contents as:

- Adult over egg

- Adult over chick

- Adult over unknown

- Adult over nothing

- Unattended egg

- Unattended chick

- Unknown (viewed remotely, could identify that a bird was present but not species or age)

- Empty (nest identified on a previous month's search but found to be inactive on this search)

- Not found (nest was identified on a previous month's search but not found on this search)

By keeping track of previously identified nests and identifying new ones throughout the season, we generated a count of unique tropicbird nests during the 2019 breeding season. Previous work at KPNWR in 2005 reported the majority of second nesting attempts were in the same location and by the same pair (U.S. Fish and Wildlife Service, unpub. data, 2019). Because we did not band or mark individual birds, we assumed a nest recorded at a specific location was used by the same pair of birds throughout the season (for example, a nest failure and subsequent re-nesting attempt in the same location was attributed to a single breeding pair).
Although our primary purpose was to census the number of nests, tracking nest fate and recording aspects of nest habitat provided additional information on phenology, nest failure rate, and nest habitat for tropicbirds at KPNWR. If the nest contained a chick, we estimated the chick's age based on its development. We also recorded three metrics of nest habitat: the landform the nest was on, the structure of the nest site (for example, what provides shade), and the first and second most dominant plant types (table 1). Landform was classified at a larger scale (10-20 meters [m] around nest), whereas structure and dominant plants were categorized at nest site scale (1-2 m).

Table 1. Habitat classification used to describe tropicbird nests.

[Landform was classified at a larger scale (approximately 10-20 m around nest), Structure and Dominant Vegetation were categorized at nest site scale (1-2 m). Dominant vegetation types were used to identify the first and second most dominant vegetation. Abbreviations: <, less than; deg, degree; > greater than; $\mathrm{m}$, meter]

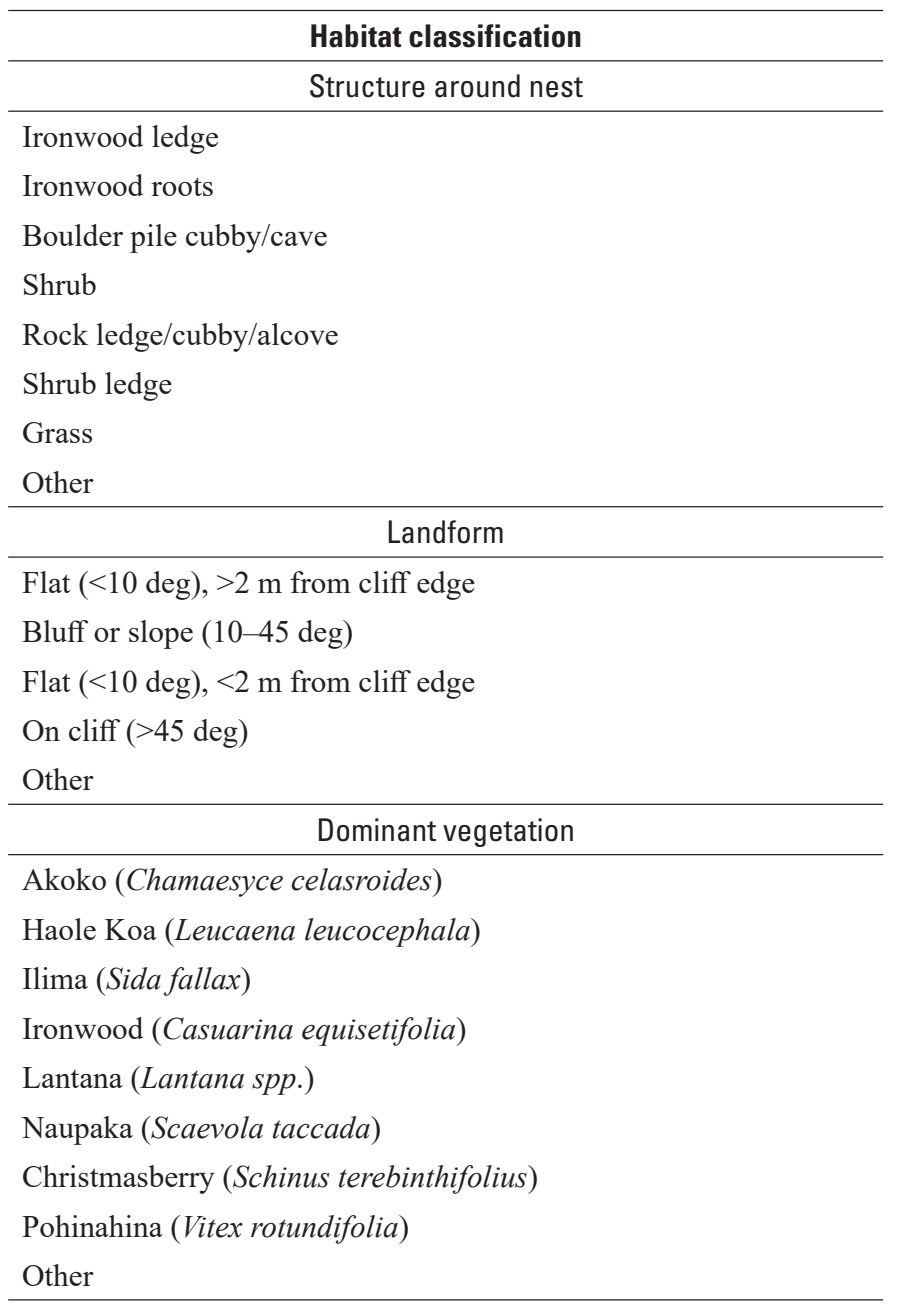




\section{Flying Bird Counts}

Red- and white-tailed tropicbirds engaging in aerial display behavior around colonies have been shown to be pre-breeders, failed breeders, or non-breeders, whereas actively nesting birds fly directly to their nests and back out to sea and are usually not observed circling/displaying around nesting areas (Fleet, 1972; Lee and Walsh-McGee, 2020; Schreiber and Schreiber, 2020; Adams and others, 2020). To supplement ground counts we counted flying/displaying red-tailed tropicbirds to estimate a total number of breeding and non-breeding tropicbirds using KPNWR (see Fleet, 1972, for similar approach at Kure Atoll). At KPNWR, this counting method could provide information to assess relative numbers of red- and white-tailed tropicbirds nesting on the refuge.

We surveyed the number of flying tropicbirds around KPNWR on May 15, 2019. Using three observers, we completed simultaneous counts of flying red-tailed and white-tailed tropicbirds at Kīlauea Point (near lighthouse), Crater Hill (upper overlook), and Mōkōlea Point (exact viewpoint identified in figure 2; see appendix table 1.1 for specific locations of remote viewing vantages). Observers determined boundaries of survey areas in advance to avoid double-counting. Specifically, we completed synchronous, 3-minute-long counts at three consecutive times every hour (for example, 10:00, 10:03, 10:06), from 10:00 to 15:00 (the time window coinciding with when most red-tailed tropicbird display activity occurs; Fleet, 1972; Tyler, 1991; Adams and others, 2020). For each synchronous count, we summed the observations from all three locations, assuming unique birds were counted in all three areas. We used the greatest sum count from the three consecutive counts to examine the hourly pattern of aerial activity throughout the survey period. We used the greatest synchronous sum count from the entire day as the maximum number of flying birds seen. Observers moved around the site as needed to be able to view all parts of the area while counting. We chose 3-minute sampling units as the minimum time needed to count all portions of an area without risk of double-counting and because the relative scarcity of white-tailed tropicbirds required more time than a simple instantaneous count to detect this species.

\section{Results}

\section{Nest Counts}

Across all visits in 2019, we identified 451 unique red-tailed tropicbird nest sites in KPNWR (387 active, 64 potential; table 2; fig. 3). During our first visit in April, we located 156 nests (117 active, 39 potential), in May 2019 we found 355 nests (276 active, 79 potential), and in July 2019 we found 268 nests (216 active, 52 potential; table 2). Note that the sum of April, May, and July nest counts does not equal the total count of unique nest sites across all visits because some unique nests were present on one, two, or all three of the visits. Across all visits, most nests were on Mōkōlea Point (63 percent), followed by Crater Hill (20 percent) and Kîlauea Point (16 percent; table 3; fig. 3). Most of the sites (80 percent) were discovered by ground-searching, whereas 20 percent of sites were on steep cliffs (east side of Kîlauea Point, west side of Crater Hill, or Crater Hill Interior cliffs) or offshore rocks (Makapili and Moku'ae'ae) and were viewed remotely through binoculars or a scope (fig. 3). During 2003 through 2007, the refuge biologist surveyed for and monitored tropicbird nests at KPNWR throughout the breeding season every 2-4 weeks (U.S. Fish and Wildlife Service, unpub. data, 2019). We present the results of those nest searches with our final nest numbers for 2019 in table 4 and figure 4. Makapili Rock and Moku'ae'ae Islet are not part of KPNWR and only were surveyed remotely in this study (similar to 2003-04); however, Moku'ae'ae was ground-searched by KPNWR in 2005-07 (range 8-10 nests, table 4; U.S. Fish and Wildlife Service, unpub. data, 2019) as well as by Raine and others (2020) in 2018-19, when 39 and 23 red-tailed tropicbird nests were found, respectively.

Table 2. Summary of unique red-tailed tropicbird (Phaethon rubricauda) nests found in Kīlauea Point National Wildlife Refuge, Kaua'i, April 8-11, May 13-18, July 1-7, and overall, in 2019.

[Active nests had a confirmed egg or chick, or, for remotely viewed nests, had an adult present for two consecutive visits, but nest contents may not have been viewable. Potential nests were defined as nests located on the ground where a bird was occupying a potential nest site, but no egg or chick were present, or when contents were unknown because site was viewed remotely and an adult was not present for two consecutive visits. If a unique nest was active on any visit (April, May, or July), we counted it as active for Total Unique Nests, otherwise it was counted as a potential nest site.]

\begin{tabular}{lrrrc}
\hline $\begin{array}{c}\text { Nest } \\
\text { status }\end{array}$ & April & May & July & $\begin{array}{c}\text { Total unique } \\
\text { nests }\end{array}$ \\
\hline Active & 117 & 276 & 216 & 387 \\
Potential & 39 & 79 & 52 & 64 \\
\hline Total & $\mathbf{1 5 6}$ & $\mathbf{3 5 5}$ & $\mathbf{2 6 8}$ & $\mathbf{4 5 1}$ \\
\hline
\end{tabular}

${ }^{1}$ Total unique nests does not equal sum of April, May, and July nest columns because some nests were present on multiple visits and included in monthly totals of active and potential nest sites. 


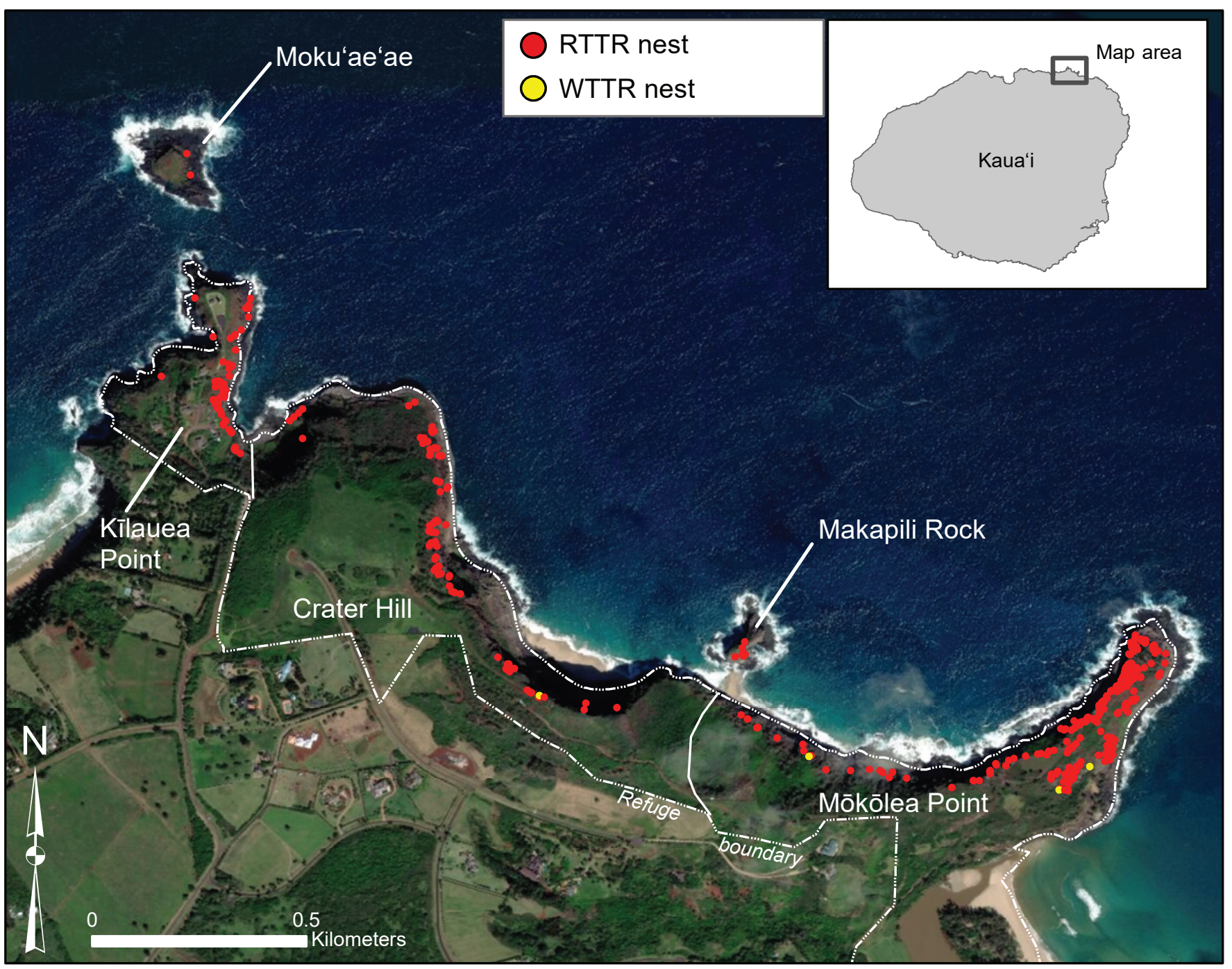

Figure 3. Kīlauea Point National Wildlife Refuge (KPNWR) showing red-tailed (Phaethon rubricauda) and white-tailed (P. lepturus) active and potential nest sites discovered during April 8-11, May 13-18, and July 1-7, 2019. Abbreviations: RTTR, red-tailed tropicbird; WTTR, white-tailed tropicbird. Thin solid white lines indic ate subdivisions of refuge used for summarizing nest counts in table 3. Makapili Rock and Moku'ae'ae Islet are managed by the state of Hawaii and are not part of KPNWR.

Table 3. Summary of nest status for all unique red-tailed tropicbird (Phaethon rubricauda) nests found in different areas of Kīlauea Point National Wildlife Refuge, Kaua'i, April 8-11, May 13-18, and July 1-7, 2019.

[Nests were either ground-located or viewed remotely. Active nests had a confirmed egg or chick, or, for remotely viewed nests, had an adult present for two consecutive visits but nest contents may not have been viewable. Potential nests were nests located where a bird was occupying a potential nest site, but no egg or chick were present or when contents were unknown because the nest was viewed remotely and an adult was not present for two consecutive visits.]

\begin{tabular}{|c|c|c|c|c|c|c|c|c|c|c|c|c|}
\hline \multirow{2}{*}{$\begin{array}{l}\text { Nest } \\
\text { status }\end{array}$} & \multicolumn{3}{|c|}{ Kīlauea Point } & \multicolumn{3}{|c|}{ Crater Hill } & \multicolumn{3}{|c|}{ Mōkōlea } & \multirow{2}{*}{$\frac{\text { Moku'ae'ae }}{\text { Remote }}$} & \multirow{2}{*}{$\begin{array}{c}\text { Makapili } \\
\text { Remote }\end{array}$} & \multirow{2}{*}{ Total } \\
\hline & Ground & Remote & Total & Ground & Remote & Total & Ground & Remote & Total & & & \\
\hline Active & 47 & 12 & 59 & 32 & 28 & 60 & 258 & 7 & 265 & 2 & 1 & 387 \\
\hline Total & 50 & 22 & 72 & 42 & 46 & 88 & 271 & 12 & 283 & 2 & 6 & 451 \\
\hline
\end{tabular}


Table 4. Current and historical (U.S. Fish and Wildlife Service, unpub. data, 2019) active nest counts for red-tailed tropicbirds (Phaethon rubricauda) at Kīlauea Point National Wildlife Refuge, Kaua'i.

[Counts include all active nests (i.e., egg or chick seen) and nests that couldn't be confirmed (i.e., viewed remotely) but had an adult present on two consecutive visits 1 . Percentages for each nesting location are proportions of the total for the year. Relative nest site locations can be found in figure 3. Makapili Rock and Moku'ae'ae Islet are managed by the state of Hawaii and are not part of Kīlauea Point National Wildlife Refuge. Abbreviations: \#, count; \%, percent]

\begin{tabular}{|c|c|c|c|c|c|c|c|c|c|c|c|c|}
\hline \multirow{2}{*}{ Nest location } & \multicolumn{2}{|c|}{2003} & \multicolumn{2}{|c|}{2004} & \multicolumn{2}{|c|}{2,32005} & \multicolumn{2}{|c|}{22006} & \multicolumn{2}{|c|}{22007} & \multicolumn{2}{|c|}{1,22019} \\
\hline & $\#$ & $\%$ & $\#$ & $\%$ & $\#$ & $\%$ & $\#$ & $\%$ & $\#$ & $\%$ & $\#$ & $\%$ \\
\hline Mōkōlea Point ${ }^{2}$ & 75 & 56 & 108 & 69 & 122 & 64 & 108 & 58 & 125 & 54 & 265 & 68 \\
\hline Crater Hill & 30 & 22 & 21 & 13 & 27 & 14 & 33 & 18 & 45 & 20 & 60 & 16 \\
\hline Kīlauea Point & 19 & 14 & 20 & 13 & 26 & 13 & 27 & 14 & 43 & 19 & 59 & 15 \\
\hline Makapili Rock & 8 & 6 & 6 & 4 & 7 & 4 & 9 & 5 & 10 & 4 & 1 & 0 \\
\hline Moku'ae'ae I. ${ }^{3}$ & 3 & 2 & 2 & 1 & 9 & 5 & 10 & 5 & 8 & 3 & 2 & 1 \\
\hline Total & 135 & & 157 & & 191 & & 187 & & 231 & & 387 & \\
\hline
\end{tabular}

${ }^{1}$ The interval between consecutive visits was significantly different during 2003-2007 (every 2-4 weeks across the entire breeding season) and our study (1-2 months from April to July). Thus, there are limitations in the ability to compare numbers through time, because the survey effort performed in 2003-2007 was greater than ours in 2019.

${ }^{2}$ Starting in 2005, searching of Mōkōlea Point was expanded to the lower east side of the point, potentially contributing to greater counts in 2005-2007 than in 2003-2004. Searches in 2019 included this expanded area as well.

${ }^{3} \mathrm{Moku}^{\prime}$ ae'ae Islet was searched by viewing it remotely 2003-2004 and 2019. Researchers visited the island in 2005-2007 and found additional nests that couldn't be viewed remotely (included in totals).

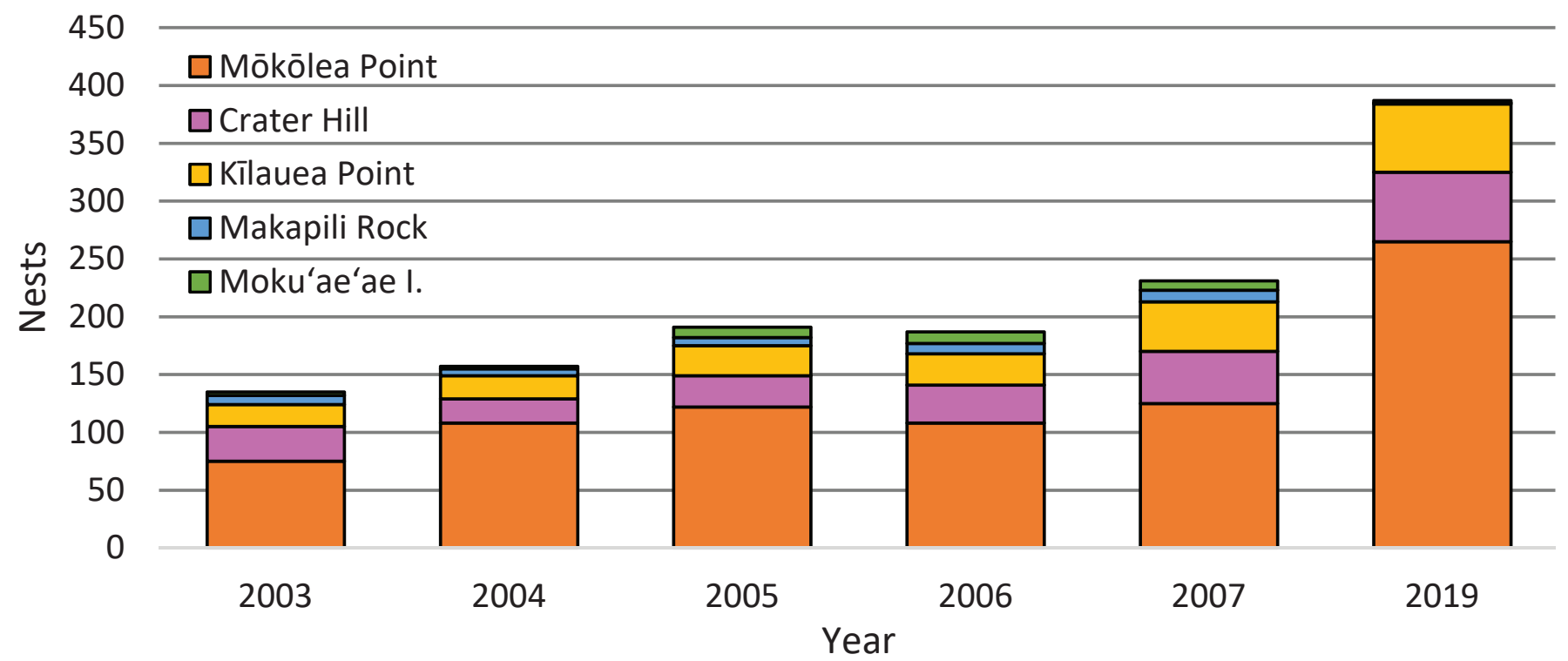

Figure 4. Current and historical (U.S. Fish and Wildlife Service, unpub. data, 2019) nest counts for red-tailed tropicbirds (Phaethon rubricauda) at Kīlauea Point National Wildlife Refuge, Kaua'i. Counts included all confirmed nests (that is, egg or chick seen) and nests that could not be confirmed (in other words, seen remotely) that were present on two consecutive visits. Nest site locations can be seen in figure 3. Starting in 2005, searching of Mōkōlea Point was expanded to the lower east side of the point, potentially contributing to higher counts in 2005-07 than in 2003-04. Searches in 2019 included this expanded area as well. Moku'ae'ae Islet was searched by viewing it remotely during 2003-04 and 2019. Researchers visited the island in 2005-07 and found additional nests that could not be viewed remotely (included here). Makapili Rock and Moku'ae'ae Islet are managed by the state of Hawaii and are not part of the Kīlauea Point National Wildlife Refuge. 
Table 5. Breakdown of tropicbird chick feathering stages used to estimate chick age in nest checks at Kīlauea Point National Wildlife Refuge and the resulting chick stages identified in the April, May, and July 2019 checks.

[Chick stages were provided by the U.S. Fish and Wildlife Service as used in central Pacific wildlife refuges (Beth Flint, oral commun., 2014) and ages adapted from Fleet (1972)]

\begin{tabular}{rlcccc}
\hline $\begin{array}{c}\text { Chick } \\
\text { stage }\end{array}$ & Description of chick feathering status & $\begin{array}{c}\text { Chick } \\
\text { age } \\
\text { (days) }\end{array}$ & $\begin{array}{c}\text { April } \\
\text { count }\end{array}$ & $\begin{array}{c}\text { May } \\
\text { count }\end{array}$ & $\begin{array}{c}\text { July } \\
\text { count }\end{array}$ \\
\hline 0 & Egg. & 0 & 117 & 223 & 92 \\
1 & All downy. & $1-14$ & - & 35 & 11 \\
2 & Scapular feathers in pin stage. & $9-17$ & - & - & 6 \\
3 & Scapular pins burst. & $15-22$ & - & - & 13 \\
4 & Secondary and tertiary wing feathers appear. & $14-21$ & - & - & 6 \\
5 & Ventral tract comes in. & $20-25$ & - & - & 4 \\
6 & Primary feathers and retricies first appear. & $21-27$ & - & - & 11 \\
7 & Dorsal feather tract comes in. & $22-35$ & - & - & 10 \\
8 & Down on neck, lower back, and flanks only. & $35-40$ & - & - & 16 \\
9 & Traces of down on lower back only. & $40-60$ & - & - & 8 \\
10 & Fully feathered ${ }^{1}$. & $157-76$ & - & - & 8 \\
- & - & Total: & $\mathbf{1 1 7}$ & $\mathbf{2 5 8}$ & $\mathbf{1 8 5}$ \\
\hline
\end{tabular}

${ }^{1}$ Chicks may fledge between 73 and 123 days (Schreiber and Schreiber, 2020).

In April 2019, we located one potential white-tailed tropicbird nest site viewed remotely on the southeast side of Mōkōlea Point above Kahili Quarry Road (fig. 3). Located in an alcove created by ironwood roots on a bluff above the road, this site had an adult present for multiple days in April but appeared empty in May and July. We assumed this nest failed or was never initiated. In May 2019, we located a second white-tailed tropicbird nest on bluffs above the Kahili Quarry Road (fig. 3). This nest was found while ground-searching. The bird was approximately $1-\mathrm{m}$ deep in a rock tunnel beneath boulders at the top of small cliffs. In July, this nest had a fully feathered chick present. Additionally, we observed a white-tailed tropicbird landing at a potential nest site directly below the upper Crater Hill overlook in May, although the exact location could not be viewed or accessed to confirm nesting. Finally, we found a potential white-tailed tropicbird nest in July on the bluffs northeast of the Nihoku predator exclusion fence; an adult was found on the ground in an ironwood root mass, less than 1-m above a nesting red-tailed tropicbird but no egg or chick was present (fig. 3).

\section{Phenology and Reproductive Success}

In April 2019, all active red-tailed tropicbird nests located with viewable contents contained an adult on an egg. In May 2019, 86 percent of active nests contained an egg and
14 percent contained a chick. All chicks found in May were downy and less than a few weeks old (table 5). In July 2019, 50 percent of active nests contained an egg, 50 percent contained a chick, and chick ages ranged from all downy (less than 2 weeks old) to fully feathered (potential fledging age; table 5). Most chicks (73 percent) were between 2 and 6 weeks old (chick stages $\mathrm{C} 3-\mathrm{C} 8$, table 5), which indicated that a peak in chick-hatching occurred from late-May to mid-June 2019.

With only three nest searches across the 2019 breeding season, our ability to determine reproductive success (in other words, how many of the eggs laid resulted in fledged chicks) was limited. However, our last check in July was after most birds are known to lay eggs and before any chicks were ready to fledge (tables 6, 7; U.S. Fish and Wildlife Service, unpub. data, 2019); therefore, we estimated a minimum nest failure rate defined as the sum of (1) active April-initiated nests that were inactive by May or July and (2) active May-initiated nests that were inactive by July. The minimum nest failure of 58 percent in 2019 equates to a maximum potential reproductive success of 42 percent (that is, if every nest that was still active in July resulted in a fledged chick, maximum reproductive success would have been 42 percent in 2019). In table 8 , we present our estimated minimum nest failure rate along with nest success from 2003 to 2007 when final nest fates were monitored (U.S. Fish and Wildlife Service, unpub. data, 2019). 
Table 6. Red-tailed tropicbird (Phaethon rubricauda) phenology measured during 2003-08 at Kīlauea Point National Wildlife Refuge, Kaua'i (U.S. Fish and Wildlife Service, unpub. data, 2019).

[Dates shown are best estimates based on when the event was first or last observed. Abbreviation: UNK, unknown.]

\begin{tabular}{lcccccc}
\hline \multicolumn{1}{c}{ Phenological event } & $\mathbf{2 0 0 3}$ & $\mathbf{2 0 0 4}$ & $\mathbf{2 0 0 5}$ & $\mathbf{2 0 0 6}$ & $\mathbf{2 0 0 7}$ & $\mathbf{2 0 0 8}$ \\
\hline First breeders display & Jan. 28 & Jan. 28 & Jan. 27 & Jan. 28 & Jan. 21 & UNK \\
\hline First egg laid & Feb. 13 & Mar. 01 & Mar. 08 & Mar. 06 & Mar. 05-12 & Mar. 21 \\
\hline Last egg laid & Aug. 20 & Jul. 23 & Aug. 03-18 & Aug. 24 & Jul. 28 & UNK \\
\hline First egg hatched & Mar. 25 & Apr. 15 & Apr. 20 & Apr. 18 & Apr. 24 & May 05 \\
\hline Last egg hatched & Oct. 01 & Sep. 06 & Sep. 08 & Aug. 22 & Sep. 10 & UNK \\
\hline First chick fledged & Jul. 06 & Jul. 01 & Jul. 09 & Jul. 06 & Jul. 10-18 & Jul. 28 \\
\hline Last chick fledged & UNK & Nov. 24 & Nov. 13 & Nov. 19 & Nov. 09 & UNK \\
\hline
\end{tabular}

Table 7. Monthly distribution of red-tailed tropicbird (Phaethon rubricauda) hatching across breeding seasons at Kīlauea Point National Wildlife Refuge, Kaua'i, 2003-05 (U.S. Fish and Wildlife Service, unpub. data, 2019).

[Monthly hatching represented as the proportion of total hatching events that occurred in that year. Abbreviation: $<$, less than]

\begin{tabular}{rcccccccc}
\hline Year & Mar. & Apr. & May & June & July & Aug. & Sep. & Oct. \\
\hline 2003 & $<0.01$ & 0.07 & 0.20 & 0.49 & 0.20 & 0.05 & 0 & $<0.01$ \\
2004 & - & 0.06 & 0.42 & 0.15 & 0.18 & 10.17 & 0.02 & - \\
2005 & - & 0.01 & 0.39 & 0.40 & 0.17 & 0.01 & $<0.01$ & - \\
\hline
\end{tabular}

${ }_{1}^{1}$ Approximately half of hatches in August 2004 were re-nests due to rat predation of chicks (U.S. Fish and Wildlife Service, unpub. data, 2019).

Table 8. Red-tailed tropicbird (Phaethon rubricauda) reproductive success measured during 2003-07 (U.S. Fish and Wildlife Service, unpub. data, 2019) and minimum reproductive failure as measured in 2019 at Kīlauea Point National Wildlife Refuge, Kaua'i.

[Hatching success rate is relative to eggs laid, fledging success rate is relative to eggs hatched, and overall success rate is chicks fledged relative to eggs laid (2003-07). Minimum failure rate is failed nests relative to active nests identified in this study.]

\begin{tabular}{|c|c|c|c|c|c|c|}
\hline \multirow{2}{*}{$\begin{array}{l}\text { Measure of } \\
\text { reproductive rate }\end{array}$} & \multicolumn{6}{|c|}{ Year } \\
\hline & 2003 & 2004 & 2005 & 2006 & 2007 & 2019 \\
\hline Hatching success & 0.89 & 0.71 & 0.77 & 0.72 & 0.66 & - \\
\hline Fledging success & 0.93 & 0.64 & 0.81 & 0.67 & 0.51 & - \\
\hline Overall success & 0.82 & 0.46 & 0.62 & 0.48 & 0.34 & - \\
\hline Minimum failure & - & - & - & - & - & 0.58 \\
\hline
\end{tabular}




\section{Tropicbird Flying Bird Counts}

Red-tailed tropicbird flight activity on May 15, 2019, was least during the morning, increased through midday, and decreased by 15:00 (table 9; fig. 5). The maximum number of flying birds counted during any synchronous survey was 83 birds at 13:06 (table 9; fig. 5). When combined with our tally of 276 active nests (considered as pairs) and 79 potential nests (considered as individuals) on the refuge in May 2019, we estimated a total minimum count of 714 red-tailed tropicbirds using the refuge at that time.

White-tailed tropicbird flight activity showed a subtle peak midday, but the maximum count of seven birds was much less than that of red-tailed tropicbirds (table 9; fig. 5). If display/flight activity is similarly proportional to nesting numbers for both species, we suggest an order of magnitude fewer white-tailed tropicbirds breed in KPNWR compared with red-tailed tropicbirds. Based on the flying-to-nesting ratio of red-tailed tropicbirds ( 0.234 birds nest ${ }^{-1}, 83$ displaying birds and 355 active/potential nests), we estimate that 30 active and potential white-tailed tropicbird nests might have been present in May 2019.

\section{Nest Habitat}

We described habitat characteristics of each red-tailed tropicbird nest we identified at KPNWR based on three parameters: general landform where the nest was located, habitat structure at the nest site, and dominant vegetation types (table 1; fig. 6). At Kīlauea Point, nest sites were primarily on more steeply sloping terrain (bluffs and cliffs), and to a lesser extent on flat ground (fig. 6). The dominant habitat structure (shade-provider) was rock ledges/alcoves without vegetation, ledges with an ironwood tree, or only an ironwood tree. On Crater Hill, we found nests primarily on cliffs or on flat ground immediately nearby cliffs, and nest structure was mostly rock ledges/alcoves followed by shrubs or ledges with an ironwood. On Mōkōlea Point, nest sites were predominantly on flat ground, and to a lesser extent on bluffs; shrubs and ironwoods provided the vast majority of habitat structure. The dominant vegetation types around tropicbird nests were ironwood trees at Kīlauea Point, Christmasberry (Schinus terebinthifolius) and ironwood at Crater Hill, and ironwood, Haole Koa (Leucaena leucocephala), and Christmasberry at Mōkōlea Point.

Table 9. Counts of flying red-tailed (Phaethon rubricauda) and white-tailed (P. lepturus) tropicbirds observed from Mōkōlea Point, Crater Hill, and Kīlauea Point on May 15, 2019, at Kīlauea Point National Wildlife Refuge, Kaua'i.

[Three consecutive three-minute-long counts were conducted synchronously by three observers, one at each site, every hour from 10:00 to 15:00. The maximum synchronous sum for all three sites/observers for each hour (highlighted in gray) was used in further analysis.]

\begin{tabular}{|c|c|c|c|c|c|c|c|c|}
\hline \multirow[b]{2}{*}{ Time } & \multicolumn{4}{|c|}{ Red-tailed tropicbirds } & \multicolumn{4}{|c|}{ White-tailed tropicbirds } \\
\hline & Kīlauea & $\begin{array}{c}\text { Crater } \\
\text { Hill }\end{array}$ & Mōkōlea & Total & Kīlauea & $\begin{array}{c}\text { Crater } \\
\text { Hill }\end{array}$ & Mōkōlea & Total \\
\hline $10: 00$ & 3 & 2 & 1 & 6 & 2 & 2 & 0 & 4 \\
\hline $10: 03$ & 4 & 3 & 5 & 12 & 1 & 3 & 0 & 4 \\
\hline 10:06 & 6 & 1 & 4 & 11 & 1 & 1 & 0 & 2 \\
\hline $11: 00$ & 8 & 6 & 5 & 19 & 1 & 1 & 0 & 2 \\
\hline 11:03 & 7 & 10 & 6 & 23 & 3 & 2 & 0 & 5 \\
\hline 11:06 & 11 & 5 & 4 & 20 & 1 & 1 & 0 & 2 \\
\hline $12: 00$ & 10 & 19 & 7 & 36 & 2 & 3 & 0 & 5 \\
\hline $12: 03$ & 12 & 22 & 15 & 49 & 1 & 2 & 0 & 3 \\
\hline $12: 06$ & 12 & 17 & 13 & 42 & 2 & 3 & 0 & 5 \\
\hline 13:00 & 28 & 22 & 19 & 69 & 0 & 4 & 1 & 5 \\
\hline 13:03 & 21 & 29 & 22 & 72 & 1 & 5 & 1 & 7 \\
\hline $13: 06$ & 24 & 32 & 27 & 83 & 0 & 3 & 1 & 4 \\
\hline $14: 00$ & 21 & 28 & 23 & 72 & 0 & 4 & 1 & 5 \\
\hline $14: 03$ & 20 & 30 & 29 & 79 & 0 & 4 & 0 & 4 \\
\hline $14: 06$ & 19 & 25 & 24 & 68 & 0 & 1 & 1 & 2 \\
\hline $15: 00$ & 7 & 10 & 15 & 32 & 0 & 1 & 0 & 1 \\
\hline $15: 03$ & 10 & 8 & 19 & 37 & 0 & 2 & 1 & 3 \\
\hline $15: 06$ & 7 & 12 & 14 & 33 & 0 & 3 & 0 & 3 \\
\hline
\end{tabular}


A

Red-tailed tropicbirds

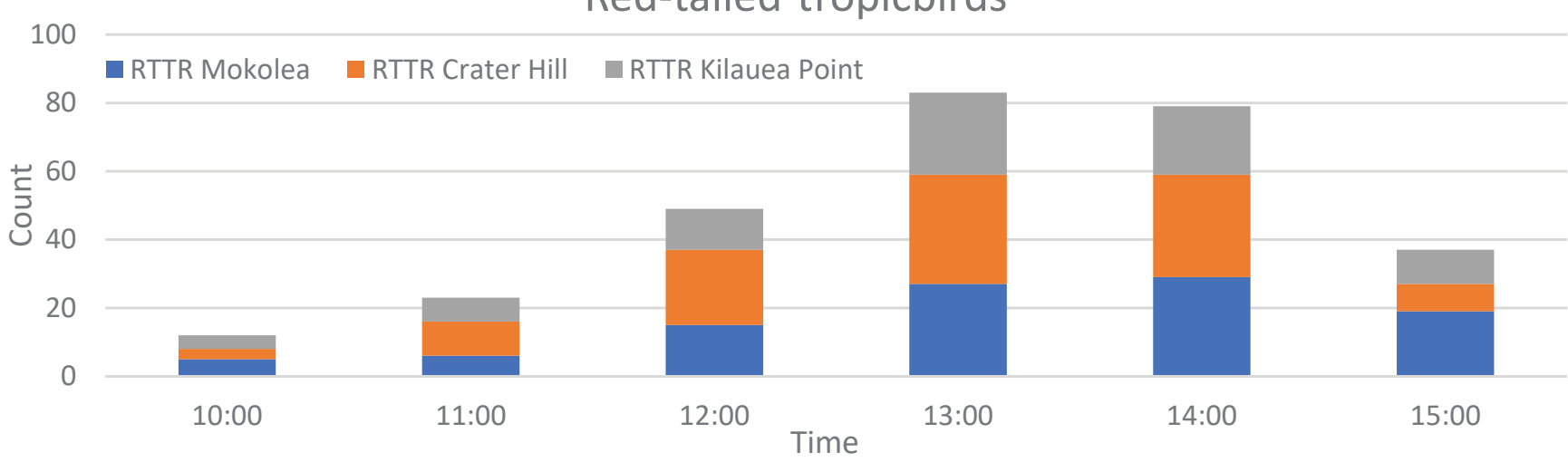

B

White-tailed tropicbirds

8

- WTTR Mokolea $\quad$ WTTR Crater Hill $\quad$ WTTR Kilauea Point

6

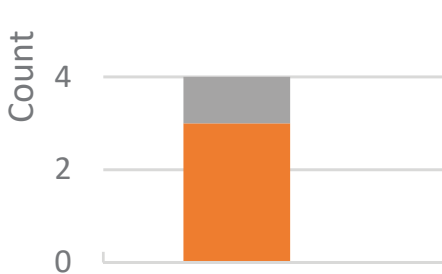

0

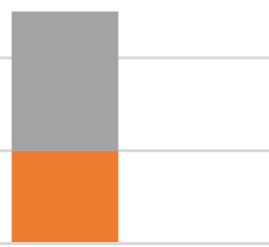

11:00

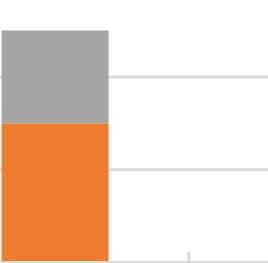

12:00

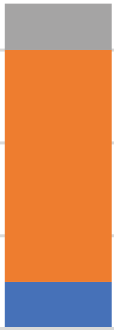

13:00

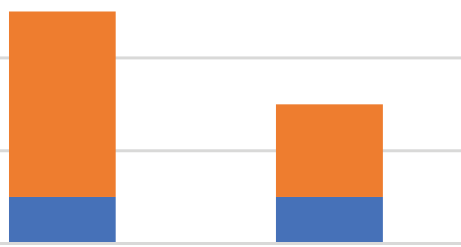

14:00

15:00

Figure 5. Counts of flying red-tailed (Phaethon rubricauda; top) and white-tailed (P. lepturus; bottom) tropicbirds observed from Mōkōlea Point, Crater Hill, and Kīlauea Point on May 15, 2019, at Kīlauea Point National Wildlife Refuge, Kaua'i.

Abbreviations: RTTR, red-tailed tropicbird; WTTR, white-tailed tropicbird. Three consecutive 3-minute-long counts were completed synchronously by three observers, one at each site, every hour from 10:00 to 15:00. The maximum synchronous sum for all three sites/observers for each hour is shown here. 


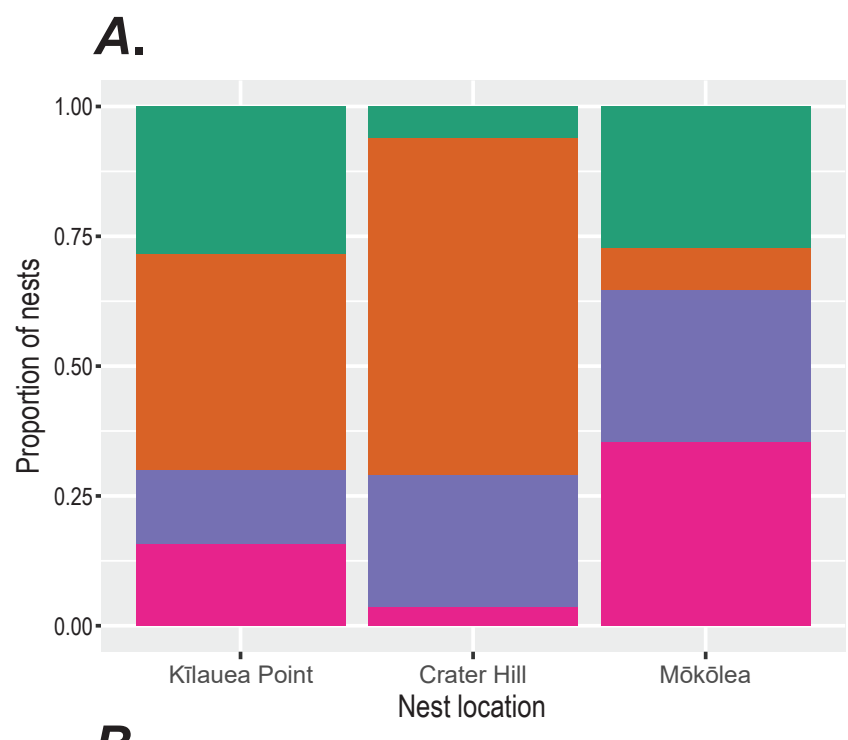

\section{Landform types}
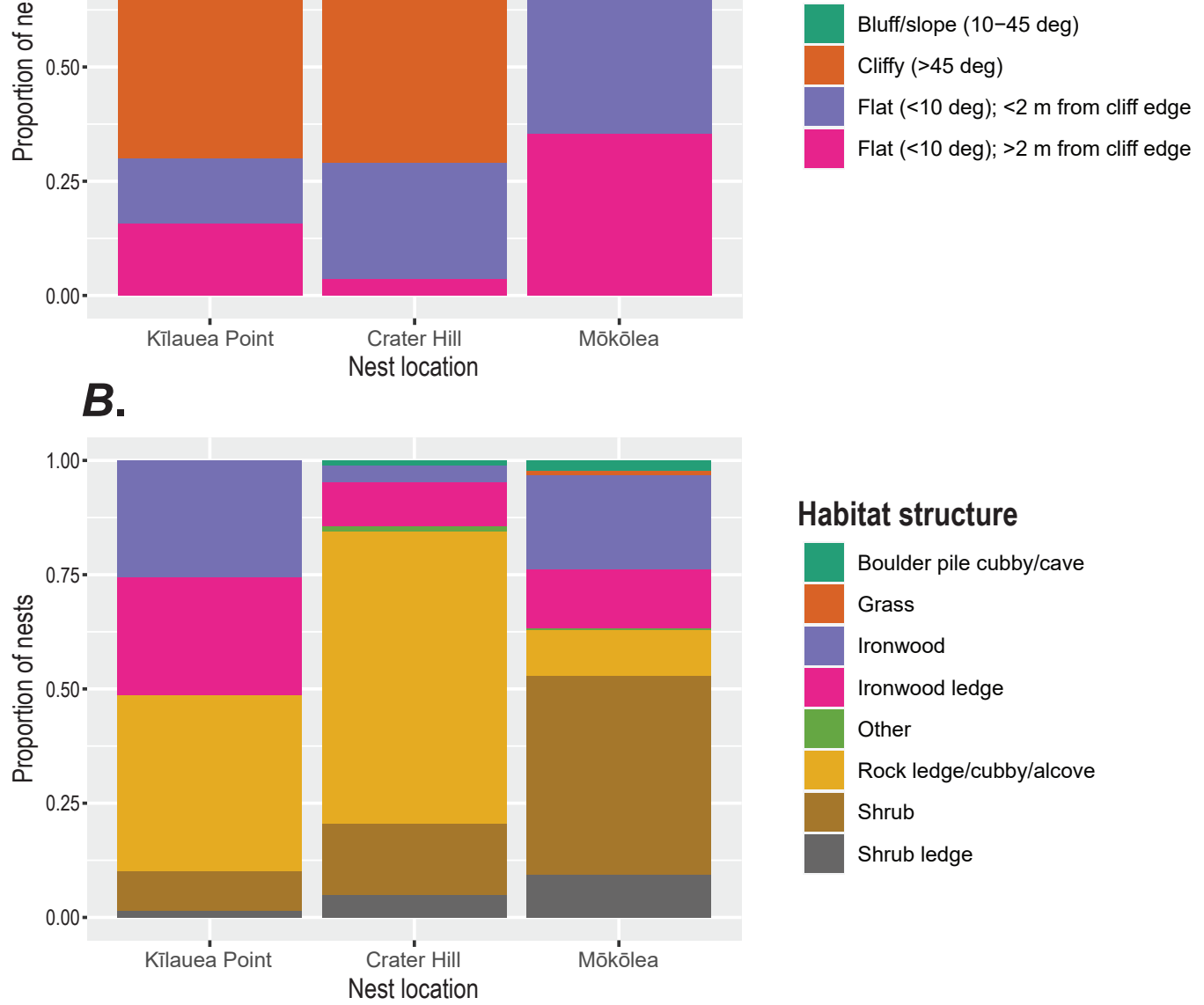

\section{Habitat structure}

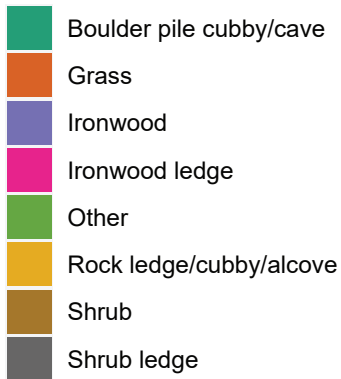

C.

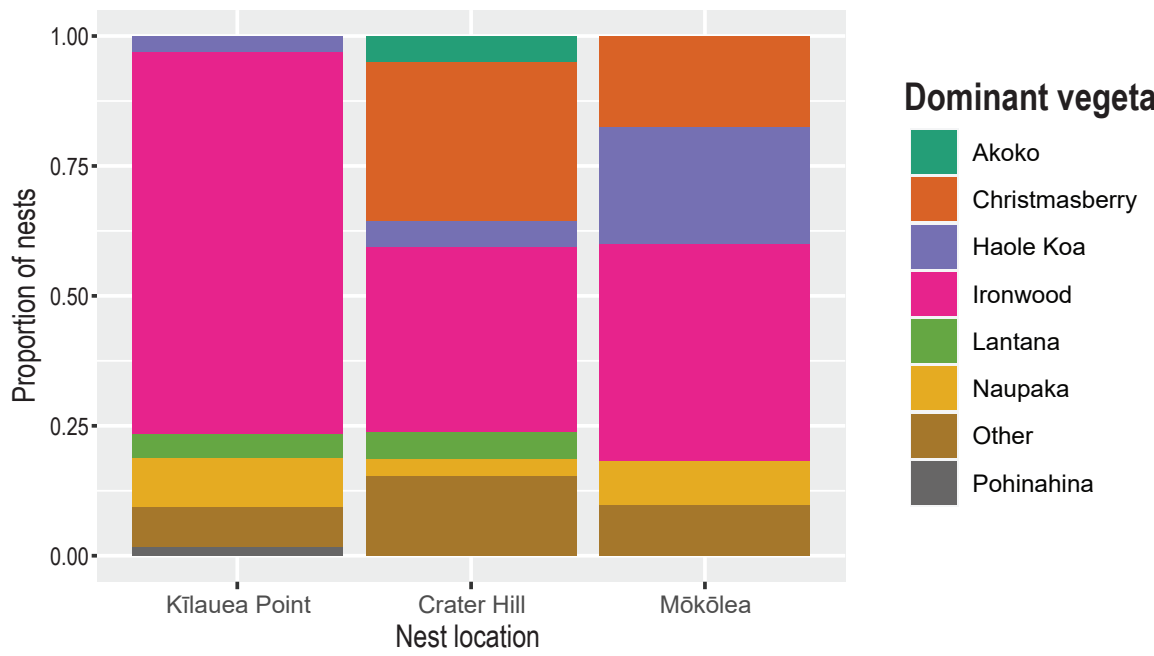

Figure 6. Proportion of $A$, landforms on which nests were located; $B$, nest habitat structures; and $C$, dominant vegetation types (if vegetation present) at red-tailed tropicbird (Phaethon rubricauda) nests at Kīlauea Point National Wildlife Refuge (KPNWR), Kaua'i, in 2019. 


\section{Discussion}

The number of red-tailed tropicbird nests at KPNWR in 2019 (451 nests; 387 active and 64 potential) appears to have increased since they were last censused during the 2000s (table 4). Based on the methods described in previous KPNWR monitoring reports (U.S. Fish and Wildlife Service, unpub. data, 2019) and direct communication with the former refuge biologist (B. Zaun, oral commun., 2019), we consider our 2019 search effort comparable with search efforts during 2005-07. Tropicbirds are susceptible to predation by feral cats and rats, for which KPNWR has active predator control programs (U.S. Fish and Wildlife Service, 2016). Although not directly evaluated in this study, red-tailed tropicbird population increases at KPNWR could be related to active predator control, like has been documented at other MHI breeding sites (VanderWerf and Young, 2014).

The proportion of nests found in different regions of the refuge in 2019 was consistent with the proportions found in the 2000s and phenology was similar (tables 4, 6, 7; fig. 4). However, because these historical nest checks were done every 2-4 weeks, and we were only able to check nests every 1-2 months throughout the breeding season, we could have missed a small proportion of failed nesting attempts. Additionally, we did not mark or band individual birds to track unique nesting and re-nesting attempts; however, the potential overestimation of nest sites (because of double-counting of pairs) that could have relocated for a second nesting attempt is unlikely because of the tendency of red-tailed tropicbirds to re-nest at the same nest site (U.S. Fish and Wildlife Service, unpub. data, 2019). Because we did not monitor final nest fates, we were limited in our ability to estimate precise red-tailed tropicbird nest success. However, the minimum nest failure rate was 58 percent in 2019. Without knowing the fate of nests after our final visit in July, this equates to a maximum potential nest success of 42 percent, which is within the range of past reproductive success estimates at KPNWR.

We only found one confirmed and three potential white-tailed tropicbird nests. The low number of identified nests is consistent with previous nest searches at KPNWR (U.S. Fish and Wildlife Service, unpub. data, 2019). White-tailed tropicbird nests are less accessible and the species has a much smaller breeding population at KPNWR than red-tailed tropicbirds (U.S. Fish and Wildlife Service, 2016). Continued searching for white-tailed tropicbirds within the refuge is unlikely to add many more nest sites.

We used an approach similar to methods at Kure Atoll (Fleet, 1972) for counting displaying tropicbirds in flight across KPNWR. Although our counts captured only a snapshot in time, we found results informative. Displaying birds contributed to an overall population estimate of 714 breeding and non-breeding birds using KPNWR in May 2019.

Red-tailed tropicbird flight activity throughout the day was consistent with other sites (for example, increasing throughout the morning and dropping off greatly after 13:00, fig. 5; Fleet, 1972). We counted flying birds on only 1 day in May 2019, thus only limited conclusions can be made. Fleet (1972) found that red-tailed tropicbird display activity was positively related to wind speed. We completed our counts during moderate trade winds (13-14 knots in Lihue); counts could have been higher or lower in stronger or weaker winds, respectively. Although more evaluation is required, counts of displaying birds could provide an alternative, less logistically demanding method to monitor tropicbird attendance and abundance at KPNWR.

Flying bird surveys can also provide a metric for estimating white-tailed tropicbird numbers within KPNWR. Relative ratios of congener seabirds attending colonies can provide useful information for relatively rare species for which nest surveys are not feasible (Catry and others, 2019); however, this approach has not been previously used for tropicbirds. Applying the ratio of displaying to nesting red-tailed tropicbirds to white-tailed tropicbirds provided us with an estimate of 30 white-tailed tropicbirds nests at KPNWR in May. This assumes that white-tailed tropicbird aerial display behavior is similar to that of red-tailed tropicbirds, both in timing and proportion relative to nesting numbers. White-tailed tropicbird aerial display peaked early in the morning at a colony in Bermuda, which challenges this assumption (Lee and Walsh-McGee, 2020), indicating that this topic warrants further investigation at KPNWR. Adopting our aerial count methods, especially on multiple days throughout the breeding season, could lead to a better understanding of the ratio of flying/displaying birds to nesting birds and allow refined population estimates for red-tailed and white-tailed tropicbirds at KPNWR and elsewhere.

Based on the three metrics we used to describe nest habitat (Habitat Structure, Landform Type, and Dominant Vegetation), red-tailed tropicbird habitat across KPNWR varied by location. Nesting was constrained to cliffs, bluffs, and cliff edges on Kīlauea Point and Crater Hill. Tropicbird nesting is likely restricted to the peripheral edges of Killauea Point due to development and human presence on top of the point (U.S. Fish and Wildlife Service, unpub. data, 2019), whereas on Crater Hill sufficient wind and cover habitat don't exist far inland from cliff edges to provide nesting habitat. On Mōkōlea Point, flat surfaces atop the point are dominated by shrub cover, exposed to adequate wind, and have minimal human presence, all of which provide good tropicbird nesting habitat, in addition to steeper slopes along the periphery of the point. 


\section{Wedge-tailed Shearwater}

\section{Species Background}

The wedge-tailed shearwater (IUCN "Least Concern"; International Union for Conservation of Nature, 2020) ranges across tropical and sub-tropical areas of the Pacific and Indian Oceans. Global population size is uncertain, but considered to be at least 5 million individuals, with approximately 318,000 breeding pairs in Hawai'i (Pyle and Pyle, 2017). The breeding population in the MHI was most recently estimated at 87,825 pairs, with most on Lehua, Kaua' $i$, and O‘ahu (Pyle and Pyle, 2017). Birds are present at nesting sites and surrounding waters predominantly during the breeding season (March-November; Harrison, 1990; Whittow, 2020). An annual and highly synchronous breeder, wedge-tailed shearwaters arrive at Hawaiian colonies early in the breeding season to bond, establish nest sites, and copulate; pre-breeding activities peak in May, after which breeding birds go to sea for a several-week exodus before returning to lay eggs in mid-June (Whittow, 2020). Incubation lasts approximately 50 days and young fledge in November 3-3.5 months after hatching (Whittow, 2020). Nesting usually occurs close to the coast and near sea level, where birds excavate burrows or occasionally nest on open ground in shaded rock alcoves or under vegetation; travel to and from the colony is nocturnal (Whittow, 2020). The number of pairs breeding at KPNWR has been estimated to be 8,000-15,000 (U.S. Fish and
Wildlife Service, 2016), but this estimate is imprecise and rigorous surveys have been limited to a small part of the refuge on the Kîlauea Point peninsula (Byrd and Boynton, 1979). Wedge-tailed shearwater reproductive success was monitored at 10 fixed plots across KPNWR in 2004 and 2005, but population size was not estimated (U.S. Fish and Wildlife Service, unpub. data, 2019; summarized in this study).

\section{Methods}

\section{Sampling Design}

We used a stratified-random sampling approach to estimate the total abundance of wedge-tailed shearwater nest sites across KPNWR. We first identified strata as unique geographic areas of the refuge to account for potential differences in nesting habitat and non-uniform nest site clustering. We then sub-divided strata where we expected high, low, minimal, or no nest site abundance. These distinctions were based on knowledge of shearwater nesting distribution gained while performing extensive ground-searching for tropicbirds across the entire refuge in April and May 2019. This scheme resulted in 12 unique strata (table 10; fig. 7). We delineated strata boundaries using recent satellite imagery in ArcGIS (version 10.7) and, based on direct observations in the field, refined in order to remove large contiguous areas lacking shearwater presence or nesting habitat.

Table 10. Summary of stratum-specific sampling effort and abundance estimation results for wedge-tailed shearwater nest sites in Kīlauea Point National Wildlife Refuge, Kaua'i, July 1-7, 2019.

[See figure 7 for stratum locations. Abbreviations: $\mathrm{km}^{2}$, square kilometer; sites $/ \mathrm{m}^{2}$, sites per square meter; NA, not applicable]

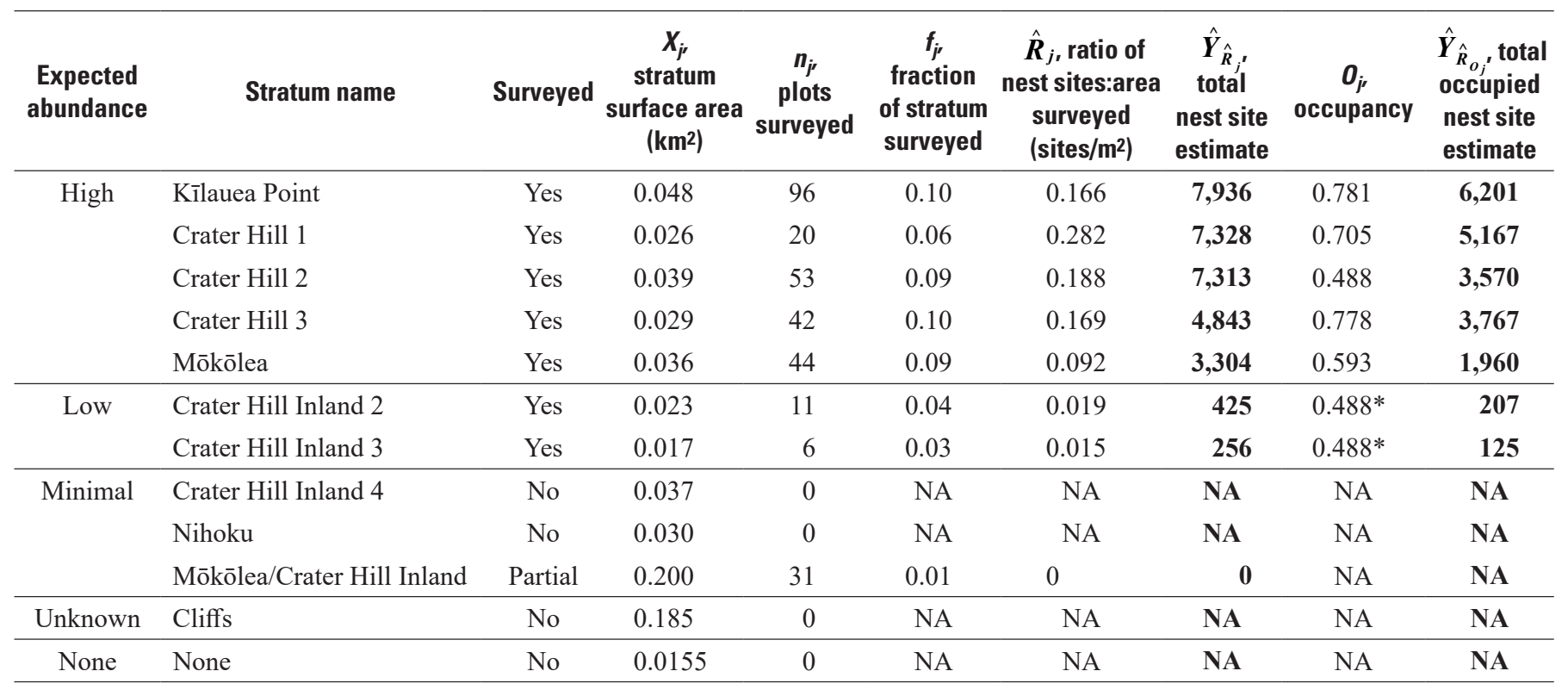

*Sample sizes were too small to calculate occupancy in strata with low expected nest site abundance. Values from neighboring stratum Crater Hill 2 were used here. 


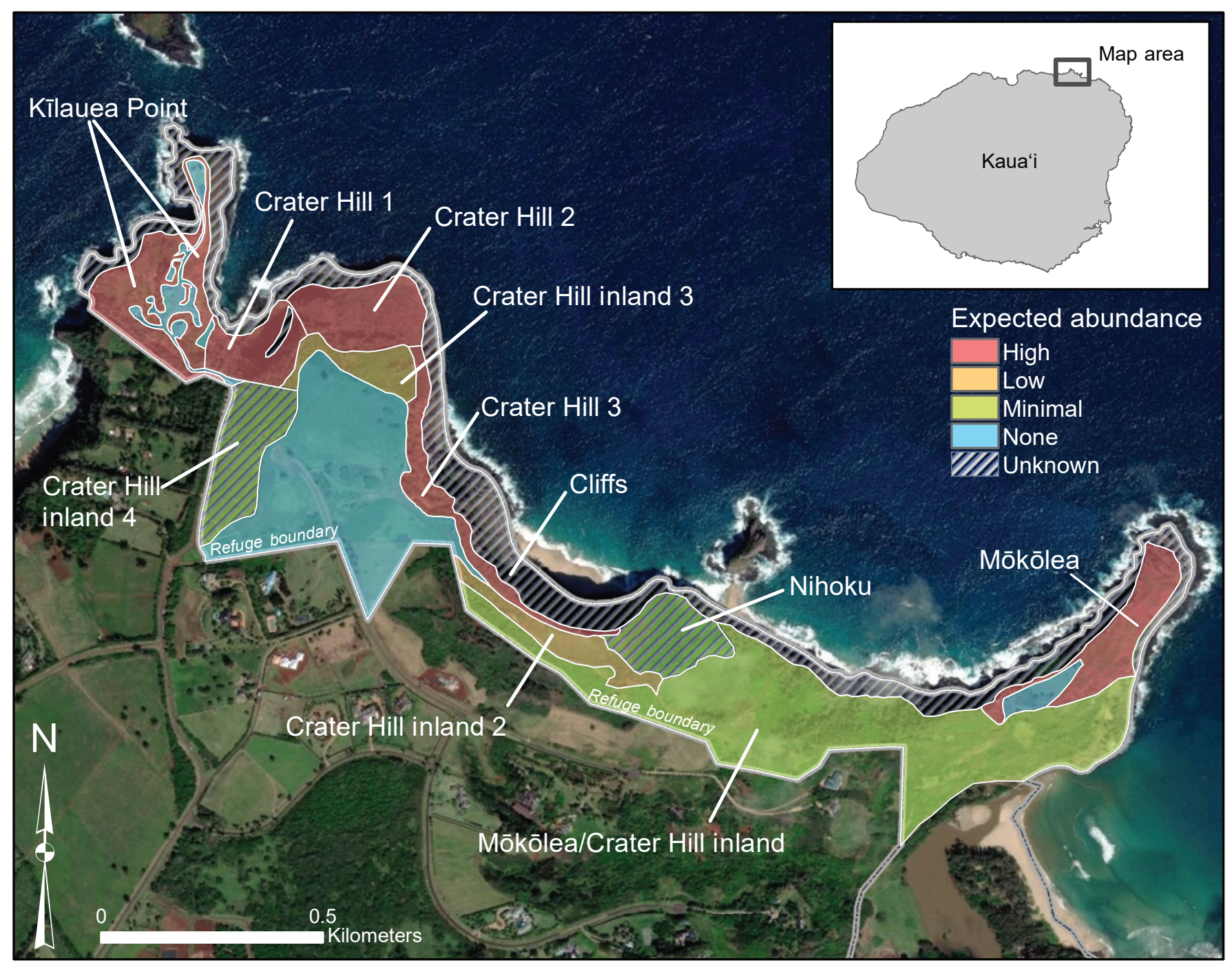

Figure 7. Strata used to sample and estimate wedge-tailed shearwater (Ardenna pacifica) abundance in Kīlauea Point National Wildlife Refuge, Kaua'i. Individual strata listed in table 10 are labeled. Color-shading indicates expected nest site abundance.

To estimate stratum-specific nest site abundance, we generated randomly located, non-overlapping circular plots within each stratum using the Random Sampling Points tool in XTools Pro (version 18; XTools, LLC, Novosibirsk, Russian Federation). We set plot radius to $5 \mathrm{~m}$ in most strata, except for some parts of Kîlauea Point where a 3-m radius was used to accommodate narrow strips of habitat. We generated enough plots to survey 10 percent of total stratum area where we expected high nest site abundance, and 5 percent of stratum area where expected nest site abundance was low or minimal. We grouped areas with no expected or observed nest site abundance, which included areas of paved or mowed surfaces, as a single stratum for reference and did not sample them. We included the cliffs forming much of the seaward edge of KPNWR as a stratum because they likely contain nesting shearwaters; however, these areas were inaccessible and were not surveyed. 


\section{Field Methods}

We surveyed for nesting wedge-tailed shearwaters during July $1-7,2019$, at KPNWR. Typically, peak egg-laying is synchronous and occurs mid- to late-June at KPNWR and regionally (Byrd and others, 1983; Pravder and others, 2015; U.S. Fish and Wildlife Service, 2016; U.S. Fish and Wildlife Service, unpub. data, 2019). We chose our survey time frame to correspond with when maximum active nest numbers and occupancy were expected. We navigated to plot locations on the ground using a handheld GPS. We occasionally moved plots in the field when part of the plot fell on either inaccessible habitat (for example, cliffs) or on non-habitat (for example, paved surfaces). To preserve randomness, we moved plots the shortest distance possible away from these features and updated location coordinates. If a plot could not be moved (for example, it was located within a narrow strip of accessible habitat), it was reduced in size and we recalculated plot area accordingly.

Once at the plot, we staked a rope with 3- and 5-m markings at the plot center to accurately determine the plot boundary. We counted all active and potential wedge-tailed shearwater nest sites in each plot's designated radius, including soil burrows, natural rock alcoves/crevices, vegetative shelters ("vegetation burrows"), and surface nest sites. A nest site was counted if any part of the radius made contact with the nest site. Although soil burrows typically are unambiguous as nest sites (for example, regardless of occupancy) and are the dominant nest type at KPNWR, other types of nest sites are often only identifiable when a bird or unmistakable sign (for example, unattended egg, guano or digging) are present. Although ambiguous surface nest sites could be difficult to count, we assumed survey timing during late incubation helped to minimize bias of undercounting nest sites that are presence-dependent; however, variability in inter- or intra-annual surface nesting likely contributes some unaccountable variance to counts. Overall, though, surface nesting is rare compared with burrow nesting at KPNWR.

We measured nest site occupancy (for example, whether a nest site had any contents as an indication that it was active at the time) in a subset of nest sites identified in plots using a systematic design that randomized site selection with a periodic interval. Beginning with the first nest site identified in the first plot of the day, we checked the occupancy of every fifth nest site encountered - cumulatively - across consecutive plots. For example, if plot $\mathrm{P}_{1}$ had 12 nest sites, we checked the occupancy of the 5th and 10th sites. If plot $\mathrm{P}_{2}$ then had seven nest sites, we checked the occupancy of the 3rd site, and so on. This sampling design scaled occupancy to the number of burrows in a plot and was achievable given time restraints. If nest occupancy could not be determined visually, we reached into a burrow to feel for a shearwater or an egg. We defined six occupancy categories:
(1) “Occupied Bird," bird present (presence of egg not confirmed);

(2) “Occupied Egg," an unattended egg was present;

(3) "Unoccupied Sign," no bird or egg present but sign present (fresh digging or guano);

(4) "Unoccupied No Sign," no signs of presence;

(5) "Unknown Sign," unable to determine occupancy but sign present; and

(6) "Unknown No Sign," unable to determine occupancy and no sign present.

In addition to counting shearwater nesting sites and evaluating occupancy, we collected information on several habitat parameters associated with each plot. We categorized the percent cover of bare soil, exposed rock, leaf litter, grass cover, shrub cover, and tree cover ( 0 percent, $1-33$ percent, 34-66 percent, 67-100 percent). We estimated cover types on the ground surface (bare soil, exposed rock, and leaf litter) in the same plane and their sum could not exceed 100 percent. Cover types above the ground surface (grass, shrub, and tree cover) were estimated in independent planes and their sum could be greater than 100 percent. We also categorized maximum tree height (less than $2 \mathrm{~m}, 2-4 \mathrm{~m}$, greater than $4 \mathrm{~m}$ ) and shrub height (less than $1 \mathrm{~m}, 1-3 \mathrm{~m}$, greater than $3 \mathrm{~m}$ ). We based the distinction between trees and shrubs on species, not height. Ironwood and Hala (Pandanus tectorius) were always classified as a tree species, regardless of height, for tree-cover measurements, and all other non-grass plants were classified as shrubs. We compared mean nest site densities to percent cover of different vegetation cover categories measured in plots across KPNWR. We measured plot slope and aspect with an inclinometer and compass, respectively.

\section{Nest Site Abundance and Occupancy Estimation}

To accommodate variable plot size, we used the ratio estimator method following Cochran (1977) to estimate stratum-specific and total wedge-tailed shearwater nest site abundance at KPNWR. All calculations were done in R (R Core Team, 2013). The ratio of total burrow count to total area surveyed across all plots in stratum $j$ was calculated as

$$
\hat{R}_{j}=\frac{y_{j}}{x_{j}}=\frac{\sum_{i} y_{i j}}{\sum_{i} x_{i j}}
$$

where

$y_{i j} \quad$ is the count of nest sites in plot $i$ in stratum $j$,

$x_{i j} \quad$ is area of plot $i$ in stratum $j$,

$y_{j} \quad$ is the total count of nest sites across all surveyed plots in stratum $j$, and

$x_{j} \quad$ is the total area of surveyed plots in stratum $j$. 
The ratio $\widehat{R}_{j}$ is equivalent to the plot-area-weighted average nest site density in a stratum and assumes that number of nest sites and plot area are correlated and proportionally related. The total nest site abundance estimate for KPNWR, $\widehat{Y}_{\widehat{R}}$, was calculated as

$$
\hat{Y}_{\hat{R}}=\sum_{j} \hat{Y}_{\hat{R}_{j}}=\sum_{j} X_{j} \hat{R}_{j}
$$

where

$$
\begin{array}{cl}
\hat{Y}_{\hat{R}} \quad \text { is the nest site abundance estimate of } \\
\text { stratum } j \text {, and } \\
X_{j} \quad \text { is total area of stratum } j .
\end{array}
$$

A variance estimate of $\hat{R}_{j}$ for each stratum $j$ was calculated as

$$
\sigma_{\hat{R}_{j}}^{2}=\frac{1-f_{j}}{n_{j} \bar{x}_{j}^{2}}\left(\sigma_{y_{j}}^{2}+\hat{R}_{j}^{2} \sigma_{x_{j}}^{2}-2 \hat{R}_{j} \sigma_{y_{j} x_{j}}\right)
$$

and the variance of the total abundance estimate as

$$
\sigma_{\hat{Y}_{\hat{R}}}^{2}=\sum_{j} X_{j}^{2} \sigma_{\hat{R}_{j}}^{2}
$$

where

$$
\begin{aligned}
& f_{j} \quad \text { is the fraction of stratum area surveyed } \\
& \left(x_{j} / X_{j}\right) \text {, } \\
& n_{j} \quad \text { is the number of plots surveyed in stratum } j \text {, } \\
& \bar{x}_{j} \quad \text { is the average area of surveyed plots in } \\
& \text { stratum } j \text {, } \\
& \sigma_{y_{j}}^{2} \quad \text { is the variance of nest site counts among } \\
& \text { surveyed plots in stratum } j \text {, } \\
& \sigma_{x_{j}}^{2} \quad \text { is the variance of plot areas among surveyed } \\
& \text { plots in stratum } j \text {, and } \\
& \sigma_{y_{j} x_{j}} \quad \text { is the covariance between plot areas and nest } \\
& \text { site counts in stratum } j \text {. }
\end{aligned}
$$

The 95-percent confidence interval of the total nest site abundance estimate was calculated as

$$
95 \% C I_{\hat{Y}_{\hat{R}}}=\hat{Y}_{\hat{R}} \pm z \sqrt{\sigma_{\hat{Y} \hat{R}}^{2}}
$$

where

$z \quad$ is the critical value (1.96).
We also generated an occupied nest site abundance estimate. We conservatively quantified a nest site occupancy in each stratum, $O_{j}$, by summing the number of sites with unequivocal presence ("Occupied Bird" and "Occupied Egg") and dividing by the total number of sites where occupancy was determined ("Occupied Bird," "Occupied Egg," "Unoccupied Sign," and "Unoccupied No Sign"). Preliminary examination indicated that occupancy differed across strata; therefore, we calculated a total occupied nest site abundance by summing stratum-specific estimates:

$$
\hat{Y}_{\hat{R}_{O}}=\sum_{j} O_{j} \hat{Y}_{\hat{R}_{j}}
$$

and we calculated the variance of stratum-specific occupancy as the variance of a binomial proportion:

$$
\sigma_{O_{j}}^{2}=\frac{O_{j}\left(1-O_{j}\right)}{m_{j}}
$$

where

$$
\begin{gathered}
m_{j} \quad \text { is the number of nest sites where occupancy } \\
\text { was determined in stratum } j .
\end{gathered}
$$

Following the procedure to calculate the variance of products (Goodman, 1960), the variance and 95-percent confidence interval (CI) of $\widehat{Y}_{\widehat{R}_{O}}$ were calculated as

$$
95 \% C I_{\hat{Y}_{\hat{R}_{O}}}=\hat{Y}_{\hat{R}_{O}} \pm z \sqrt{\sum_{j} O_{j}^{2} \sigma_{\hat{Y}_{\hat{R}_{j}}}^{2}+\hat{Y}_{\hat{R}}^{2} \sigma_{O_{j}}^{2}-\sigma_{O_{j}}^{2} \sigma_{\hat{Y}_{\hat{R}_{j}}}^{2}}
$$

We chose to represent stratum area ( $X_{j}$ in equations [2] and [4]) as surface area. Because much of KPNWR is steeply sloping and plot boundaries were determined by measuring plot radius on the land surface, using planimetric area for abundance extrapolations would underestimate nest site abundance. To calculate surface area in each stratum, we obtained a 10-m resolution digital elevation model from the National Elevation Dataset (U.S. Geological Survey, 2013). This elevation raster was projected to Universal Transverse Mercator projection (Zone 4 North, North American Datum of 1983) and converted to a surface area raster using the raster and sp packages in R (Pebesma and Bivand, 2005; Hijmans, 2019). We calculated stratum-specific surface area by summing the surface area values of raster cells in each stratum using XToolsPro (version 18; Zonal Statistics tool; XTools, LLC, Novosibirsk, Russian Federation) in ArcMap (version 10.7; Environmental Systems Research Group, Redlands, California). 


\section{Results}

\section{Field Sampling Effort}

We extensively sampled 7 of the original 12 strata identified ( 5 with high expected nest site abundance and two with low expected abundance) and counted wedge-tailed shearwater nest sites in 303 plots (table 10). Of the three strata with unknown/minimal expected abundance, we explored and sampled some plots in one (Mōkōlea/Crater Hill Inland) but did not explore or plot-sample the other two (Nihoku, Crater Hill Inland 4) because of logistical constraints and accessibility. We did not sample the stratum with no abundance (paved or mowed surfaces) nor did we sample the Cliffs stratum because it was inaccessible.

We achieved an areal sampling coverage $\left(f_{j}\right)$ at or near our 10-percent target in four of the five high abundance strata (9-10 percent). In the fifth, Crater Hill 1, we achieved 6 percent coverage because a part of this stratum is below a cliff band and was inaccessible (fig. 7; table 10). However, this area had many shearwater burrows that were remotely visible and generally is similar in habitat to the sampled part of the stratum; therefore, we chose to include this area in abundance estimations. We achieved 3-4 percent areal sampling coverage in the two low-expected-abundance strata, below our target of 5 percent (table 10), because of extremely dense vegetation that prevented access to some plots. Overall, we surveyed 303 plots, detected 2,695 nest sites, and checked occupancy at 532 nest sites. Almost all burrows were short enough to be checked by hand; we were able to determine occupancy (Occupied Bird, Occupied Egg, Unoccupied No Sign, Unoccupied Sign) for 96 percent of the nest sites checked.

\section{Nest Site Abundance and Occupancy Estimation}

The ratio of nest sites to surveyed area $\left(\widehat{R}_{j}\right.$, the plot-area-weighted nest site density) in strata with high expected abundance was greatest in Crater Hill 1 (0.282 nests per square meter $\left.\left[\mathrm{m}^{-2}\right]\right)$, less in Crater Hill 2, Crater Hill 3, and Kīlauea Point 1 (0.166-0.188 nests $\left.\mathrm{m}^{-2}\right)$, and least in Mōkōlea (0.092 nests $\mathrm{m}^{-2}$; table 10). The ratio of nest sites to surveyed area $\left(\widehat{R}_{j}\right)$ was much less in strata with low expected abundance
(0.015-0.019 nests $\left.\mathrm{m}^{-2}\right)$. Although we did not detect any nest sites in or when traveling between plots in the Mōkōlea/Crater Hill Inland stratum, we did not sample at or near the desired 5 percent of stratum area. We conservatively classified this stratum as having unknown or minimal shearwater abundance, and it is unlikely that large numbers of shearwaters nest in this stratum. Likewise, we were not able to explore or sample the Crater Hill Inland 4 or Nihoku strata and classified them as having minimal/unknown expected abundance; based on habitat and location, it is unlikely that large numbers of shearwaters nest here. We estimated a total of $31,405 \pm 3,476$ (95-percent CI) wedge-tailed shearwater nests within the entire refuge area.

Occupancy varied significantly among high-expected-abundance strata (mean 67 percent; range 49-78 percent; chi-shared $=34.36, \mathrm{df}=4$, $\mathrm{p}$-value $<0.0001$; table 10). Because so few nests were present in low-expected-abundance strata (Crater Hill Inland 2 and 3), sample sizes were too low to robustly assess occupancy or compare with other strata. We assigned to these strata the occupancy rate of Crater Hill 2 because it is most similar in habitat. We calculated an overall occupied nest site estimate of 20,998 $\pm 2,686$ (95-percent CI). Either of these estimates (total nest sites or occupied nest sites only) could be considered a minimum because we were unable to access and sample extensive cliff habitat where shearwaters certainly nest.

\section{Nesting Habitat Characteristics}

Nest site densities at the plot level corresponded positively with percentage of bare soil and negatively with percentage of leaf litter, grass cover, and shrub cover in sampled plots (fig. 8). Nest site densities were greater where tree cover was low to moderate (1-33 percent or 34-66 percent) compared with plots with no or extensive tree cover ( 0 percent or $67-100$ percent; fig. 8). Although nest site densities corresponded negatively with percent exposed rock, most exposed rock at KPNWR is on cliffs, which were not sampled. The greatest nest site densities in any habitat cover type and coverage estimation category were in plots with 67-100 percent bare soil cover (fig. 8). 

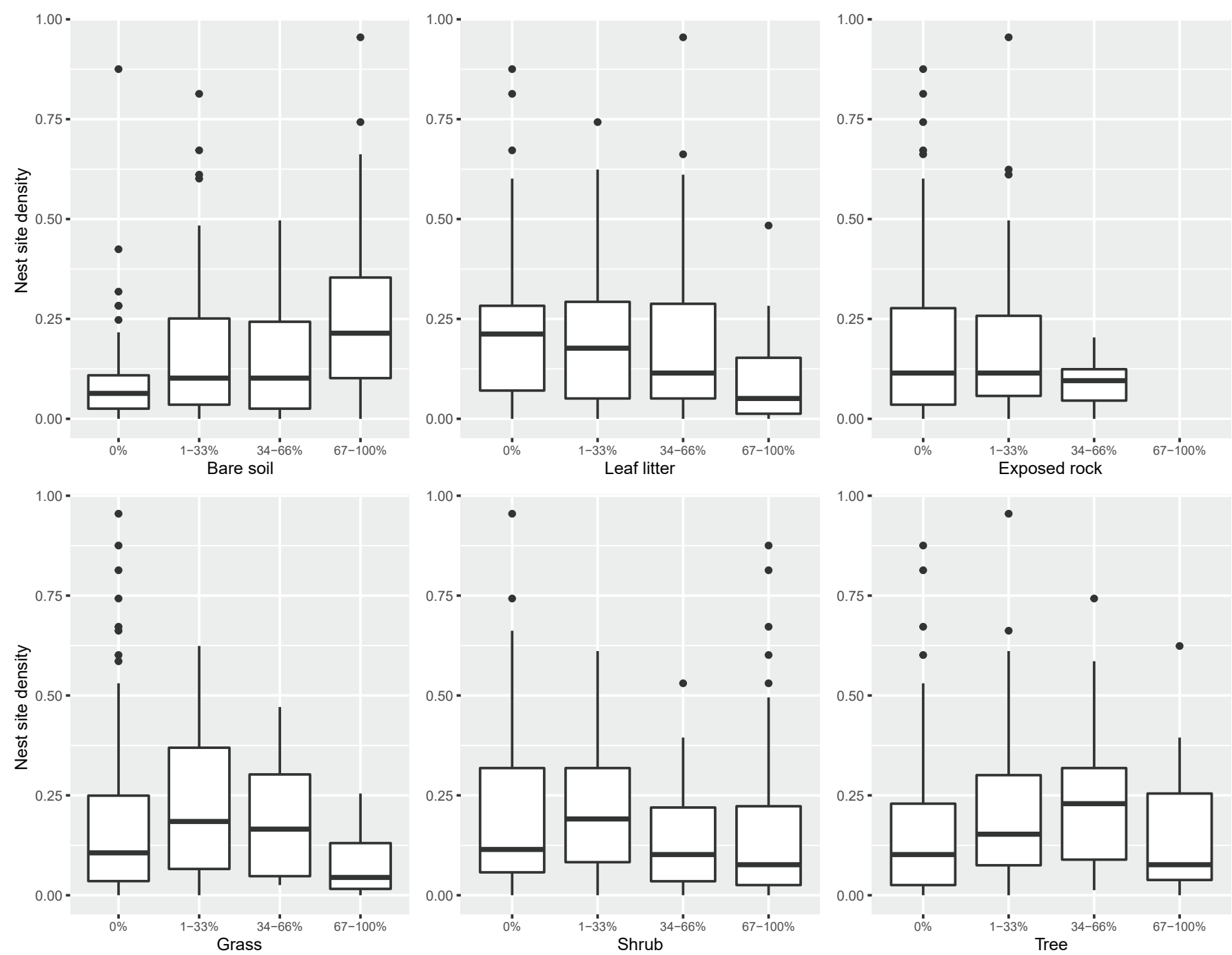

Figure 8. Wedge-tailed shearwater (Ardenna pacifica) nest site density (nests $\mathrm{m}^{-2}$ ) by coverage estimation categories (0 percent, 1-33 percent, 34-66 percent, 67-100 percent) within habitat cover types measured in sampling plots across Kīlauea Point National Wildlife Refuge, Kaua'i, in July 2019. The black line in box represents the median, the box represents the inter-quartiles (25 percent and 75 percent), the whiskers extend to the furthest point within 1.5 interquartile ranges, and dots are any additional points beyond the whiskers. Surface-cover types include bare soil, leaf litter, and exposed rock; above-ground cover types include grass, shrub, and tree cover. 


\section{Discussion}

We estimated 20,998 $\pm 2,686$ occupied wedge-tailed shearwater nest sites $(31,405 \pm 3,476$ total nest sites) were present in July 2019 throughout KPNWR. Most wedge-tailed shearwater nest sites were along Crater Hill (64 percent; estimates from all Crater Hill strata combined), followed by Kīlauea Point (25 percent), and Mōkōlea Point (11 percent). At the plot level, greater densities of nest sites generally were found where vegetation cover was low to moderate and bare soil cover was extensive; these characteristics could provide the best opportunities for shearwaters to excavate nesting burrows-the predominant nest type at KPNWR.

During the past several decades, the wedge-tailed shearwater population at KPNWR is thought to have increased in number (U.S. Fish and Wildlife Service, 2016). Historical surveys in 1978-81 identified approximately 2,411 burrows in areas comparable to our general study area in KPNWR (Byrd and Boynton, 1979), but most rigorous work was performed on Kỉlauea Point itself (Byrd and others, 1983). More recently, monitoring of reproductive plots was done in the 2000s (U.S. Fish and Wildlife Service, unpub. data, 2019) and although not measured, the overall number of burrows at KPNWR was thought to have increased since prior decades. The estimated number of nest sites for wedge-tailed shearwaters in our study was greater than the most recent (previous) estimate $(8,000-15,000$ breeding pairs; U.S. Fish and Wildlife Service, 2016; Pyle and Pyle, 2017); however, that estimate was based on crude extrapolations of density and area with no reported methods or actual sampling. Additionally, ground surveys of Moku'ae'ae Islet (nearby but not part of KPNWR; not studied herein) found 291-848 and 406-695 breeding pairs in 2018 and 2019, respectively (Raine and others, 2020), indicating that this site represents a small but important part of the greater KPNWR wedge-tailed shearwater breeding population. Although wedge-tailed shearwater abundance has potentially increased at KPNWR over the last 40 years, our results are the first robust refuge-wide census and quantitative comparisons with past estimates would be unreliable. The revised population estimate provides new information with which to evaluate the MHI metapopulation and will be useful when compared to other wedge-tailed shearwater breeding colonies throughout the region.

Our goal was to estimate the number of wedge-tailed shearwaters that are potentially breeding at KPNWR and also provide a robust method for future assessments. During the late incubation period, we counted all nest sites regardless of occupancy and also estimated occupancy for a more-refined breeding population estimate. It is important to consider survey timing and methods when comparing to other sites or at KPNWR in the future. The total number of nest sites is one metric by which to assess maximum potential breeding population size across sites and years; however, wedge-tailed shearwater colonies rarely achieve 100-percent occupancy (Byrd and others, 1983; Garkaklis and others, 1998; Dunlop and others, 2002; Dyer and others, 2005). Although wedge-tailed shearwaters are extremely site-faithful, burrow persistence - as a function of substrate, weather/erosion, and bird maintenance - could play a large role in the use of total nest sites as a measure of breeding population size, or breeding potential, across sites and years, and the total number of burrows present in a season is not necessarily a good predictor of annual breeding participation or breeding success (Byrd and others, 1983; Dunlop and others, 2002). On the other hand, occupancy and breeding participation can vary annually with large-scale ocean conditions that affect bird health and breeding propensity (Dunlop and others, 2002) and the overall abundance of potential breeding birds faithful to a colony might remain unchanged.

Overall, we estimated a 67-percent nest site occupancy rate at KPNWR in 2019, which could be interpreted as breeding participation for the year. Limited data from wedge-tailed shearwater monitoring plots at KPNWR in 2004 found a slightly greater breeding participation rate of 84 percent by measuring occupancy during the same nesting period (U.S. Fish and Wildlife Service, unpub. data, 2019). We only included nest sites with a bird or an unattended egg in our occupancy estimate, assuming that sign (for example, guano, digging) during the late incubation stage of the breeding season reflected prospecting birds that did not lay an egg. We also assumed that presence of a bird during the daytime implied presence of an egg, representing a breeding attempt, although this assumption has been shown to be less reliable at night when additional non-breeding/prospecting birds may be present (Garkaklis and others, 1998). Future surveys could benefit by confirming the presence of an egg when assessing occupancy. Other studies that prioritize the measurement of annual reproductive output often conduct surveys for chicks only during late chick-rearing period; total burrow counts, as well as sign of prior occupancy (for example, guano, digging, feathers) that might be interpreted as failed nesting attempts, are sometimes measured to quantify breeding participation and reproductive success (for example, VanderWerf and others, 2014). Late-stage nest checks could benefit by minimizing the overestimation of early season occupancy among prospecting non-breeders, although actual breeding participation (eggs laid) will remain unknown.

Our methods were labor- and time- intensive and were not designed to be repeated annually; however, our methods could be repeated periodically in the future to reassess overall abundance, distribution, and habitat changes for wedge-tailed shearwaters nesting at KPNWR. Fixed plots were established to measure wedge-tailed shearwater reproductive success at KPNWR in 2004 and 2005. Future monitoring work to measure interannual trends in abundance and productivity could reestablish these plots, or create new randomly selected fixed-plots, to measure total number of burrows, breeding participation (eggs laid in burrows during incubation), and fledging success (chicks in burrows during late chick-rearing), as recommended by Citta and others (2007) and previous refuge biologists (U.S. Fish and Wildlife Service, unpub. data, 2019). 


\section{Red-footed Booby}

\section{Species Background}

Red-footed boobies (IUCN "Least Concern"; International Union for Conservation of Nature, 2020) are distributed across the world's tropical oceans with an estimated 300,000 breeding pairs globally (Schreiber and others, 2020). Hawai' $i$ is home to approximately 12,000 breeding pairs, with the largest colonies in the Northwestern Hawaiian Islands (Pyle and Pyle, 2017). In the MHI, most of the total estimated 4,500 pairs of red-footed boobies breed on Lehua, Kaua 'i, and O'ahu (Pyle and Pyle, 2017), and a new colony was recently established on Maui (Learned and others, 2020). Red-footed boobies nest in trees and shrubs, commonly using ironwood and Christmasberry at KPNWR (U.S. Fish and Wildlife Service, 2016). Though present in MHI year-round, breeding predominantly takes place between February and October and is somewhat synchronous (VanderWerf and others, 2007; Russell and VanderWerf, 2010; U.S. Fish and Wildlife Service, 2016). Red-footed boobies lay single-egg clutches that are incubated for 45 days; fledging can take place between 90 and 135 days (Schreiber and others, 2020).

At KPNWR, the breeding population of red-footed boobies increased from less than 100 pairs in the $1960 \mathrm{~s}$ (Richardson and Bowles, 1964) to several hundred pairs in the 1980s (Byrd and Zeillemaker, 1981; Pyle and Pyle, 2017). Recent surveys from 2004 to 2008 reported an average of 1,882 breeding pairs at KPNWR (U.S. Fish and Wildlife Service, 2016). During that time, counts typically were done in mid- to late-May, when most eggs had hatched and chicks were 1-8 weeks old (most chick-hatching occurred mid-Aprilmid-May; U.S. Fish and Wildlife Service, unpub. data, 2019). This phenology also was consistent with information from reproductive plots monitored in 1999 (U.S. Fish and Wildlife Service, unpub. data, 2019).

\section{Methods}

\section{Visual Surveys}

At KPNWR, red-footed boobies nest on ocean-facing bluffs and cliffs from near the Nihoku predator exclusion area, westward along Crater Hill to the embayment just east of the Kīlauea Point peninsula (fig. 9). Previous monitoring divided this area into three subcolonies because of viewability and access: Crater Hill West (which can be viewed from the Kîlauea Point peninsula), Crater Hill Interior (viewable from several vantages along the Crater Hill cliff top), and Crater Hill East (viewable from near the Nihoku predator exclusion fence and from Mōkōlea Point; fig. 9). We counted nesting red-footed boobies in these three subcolonies to estimate total breeding population size at KPNWR by using a three-tiered approach that included ground-based visual counts, ground-based photographic counts, and aerial photographic counts.

During May 13-17, 2019, we completed visual counts of nesting red-footed boobies from vantage points where this species has been historically counted at KPNWR (fig. 9; U.S. Fish and Wildlife Service, unpub. data, 2019; see appendix table 1.1 for specific locations of remote viewing vantages). For the Crater Hill West colony, we counted from the red-footed booby interpretive sign on the Killauea Point peninsula. We counted the Crater Hill Interior colony from the Crater Hill lower overlook. Some nests that are on cliffs directly below this viewpoint are not visible; however, we maintained this viewpoint to be consistent and comparable with past results. For the Crater Hill East colony, we counted from a location just downslope (north) of the Nihoku predator exclusion fence to maintain consistency with past surveys. This vantage is low relative to the nesting colony and the visibility of many nests is limited by vegetation. Therefore, we also counted this colony from the Quarry viewpoint on Mōkōlea Point, which is farther away, but provides a better view.

For all ground-based visual counts, observers utilized a spotting scope and binoculars to count unique nests. We performed replicate counts for the Crater Hill West and Crater Hill East colonies to measure observer variability. For nests, we only counted adult birds on a nest (presumably incubating, or with a chick present) or nests with unattended chicks. Counts of individual birds, including roosting birds, can be informative, but attendance of non-breeding birds or the mates of incubating or chick-guarding individuals can be variable throughout the day based on the timing of foraging trips as dictated by phenology and environmental conditions (Adams and others, 2020). For these reasons, we kept our visual counts to just nesting birds. The seasonal timing of our surveys in 2019 was similar to that of historical counts (mid-late May) and coincides with late egg-laying and early mid chick-rearing for this species at KPNWR. 


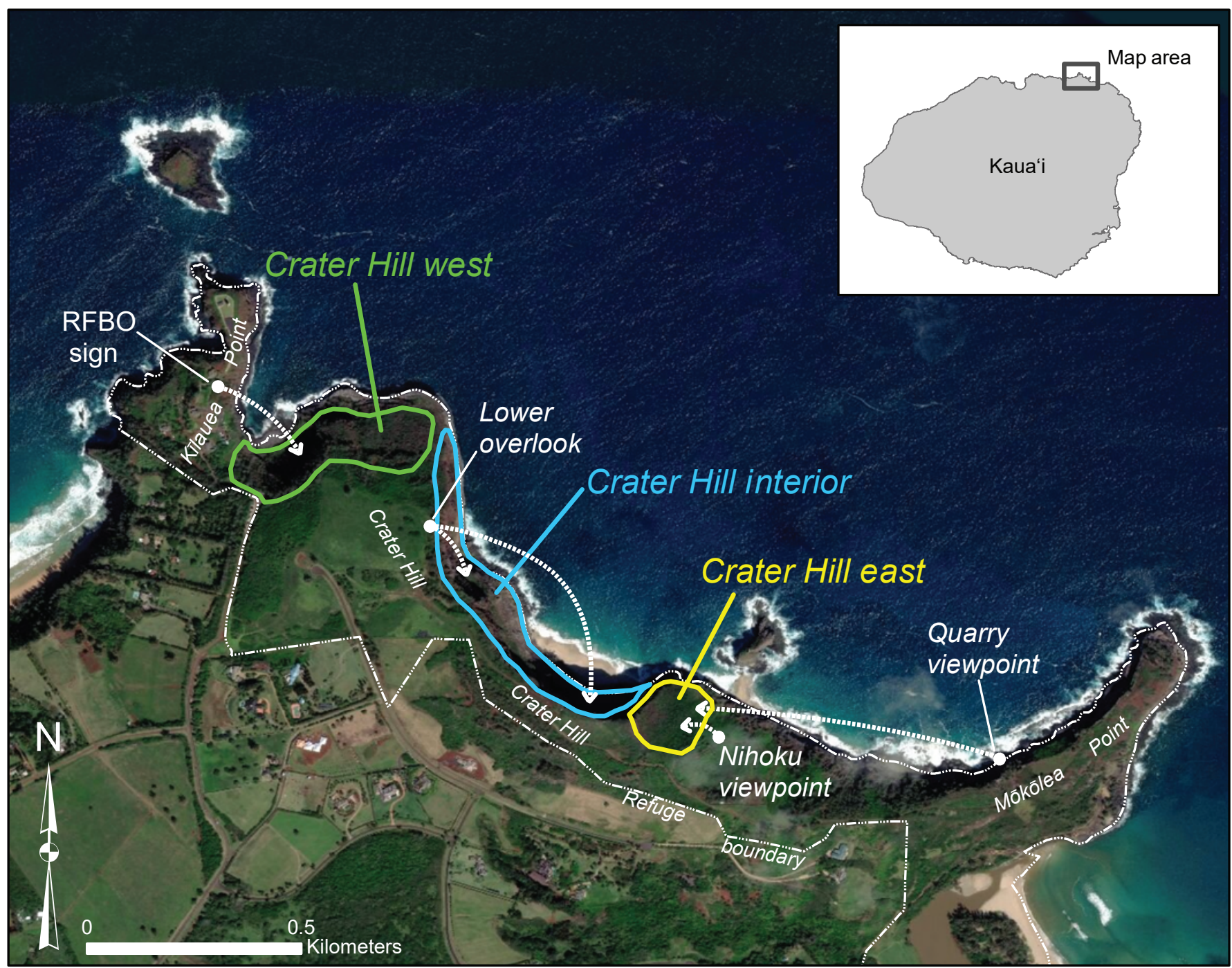

Figure 9. Kīlauea Point National Wildlife Refuge, Kaua'i, showing red-footed booby (Sula sula) sub-colony areas. Viewpoints are labeled and white dashed arrows indicate vantages used to count subcolony areas.

Repeating ground-based counts using methods and locations employed in the past allowed for a direct comparison with previous population counts. However, counting large colonies of birds at a distance is challenging. For example, nests can be partly or completely obscured by vegetation, which can change over time. Perhaps more importantly, significant variability can exist across observers when classifying the nesting status of partially obscured birds as a result of nest visibility. Some viewers could infer from bird posture that a nest exists, even if they cannot see the actual nest, whereas others could be more conservative and decline to count questionable cases as nests. This situation is compounded because observers are required to rapidly classify hundreds or thousands of individual birds as well as maintain locational reference in a colony. Trying to control for these sources of potential variability, especially among many different observers through time, is difficult without a large amount of training, inter-observer calibration, and estimation of error within and among observers (Frederick and others, 2003). Although counts of nesting red-footed boobies were consistently completed by the same individuals at KPNWR during the 2000s (U.S. Fish and Wildlife Service, unpub. data, 2019), and we followed methods described in previous reports, we had no way to ensure comparability with these counts. We present our results with results from prior surveys, but we caution interpretation of direct comparisons among studies. 


\section{Photo Counts}

To evaluate ground-based visual counts and assess variability among methods, we also employed photographic techniques to count nesting red-footed boobies at KPNWR. First, we photographed all red-footed booby colony areas at the same viewpoints where visual counts were done, except for the Nihoku viewpoint (fig. 9). We used a Sony a7rii camera (42 megapixel full-frame) equipped with a Sony 100-400 millimeter (mm) F4.5-5.6 G lens (Sony Coorporation of America, New York, New York, U.S.) to allow sufficient resolution to count nests and birds. We achieved pixel resolutions (as a function of camera resolution, focal length, and distance to birds) of $0.28-0.91$ centimeter $(\mathrm{cm})$ pixel $^{-1}$ for photos used for refuge-wide population estimates (table 11). In addition, photos of the Crater Hill West colony were taken at two focal lengths $\left(100 \mathrm{~mm}, 0.84-2.03 \mathrm{~cm} \mathrm{pixel}^{-1} ; 300 \mathrm{~mm}\right.$, $0.28-0.68 \mathrm{~cm} \mathrm{pixel}^{-1}$ ) to test the effect of pixel resolution on nest counts. These photo sets were taken within 5 minutes of each other to minimize variability in numbers of roosting birds at the colony. We only used the higher resolution photos (300-mm focal length) for refuge-wide population estimates.

Table 11. Visual and photographic red-footed booby (Sula sula) survey results from May 2019 at Kīlauea Point National Wildlife Refuge, Kaua'i.

[Counts are summarized for each sub-colony, vantage (including distance to colony), and method (including camera lens focal length). For visual counts where replicates were conducted, the mean nest count and range are shown. For photo counts, photo information and total red-footed booby (RFBO) objects identified are provided, as well as categorized counts of nesting, roosting, and unknown status birds. Specific method and count combinations used for total nest estimates at bottom of table are indicated by unique numbers in brackets. Ranges of total visual counts were calculated from minimum and maximum replicates of individual colony/vantage counts, when available. Total photographic counts include definitive nests as well as portion of unknown RFBO objects that are likely nests based on the nest:roost ratio from the specific sub-colony/photo set. Ranges of total photographic nest counts were calculated as definitive nests (minimum) to all definitive nests and unknowns combined (maximum). Abbreviations: Unk, unknown; m, meter; NA, not applicable; $\mathrm{mm}$, millimeter; $\mathrm{cm} /$ pixel, centimeter per pixel]

\begin{tabular}{|c|c|c|c|c|c|c|c|c|c|}
\hline \multirow[b]{2}{*}{$\begin{array}{l}\text { Vantage point } \\
\text { (distance) }\end{array}$} & \multirow[b]{2}{*}{ Method } & \multirow[b]{2}{*}{ Date } & \multirow[b]{2}{*}{ Reps } & \multicolumn{3}{|c|}{ Photo information } & \multicolumn{3}{|c|}{ Counts } \\
\hline & & & & $\begin{array}{l}\text { Pixel } \\
\text { resolution }\end{array}$ & $\begin{array}{c}\text { Number of } \\
\text { photos }\end{array}$ & $\begin{array}{c}\text { Total } \\
\text { RFBO } \\
\text { objects }\end{array}$ & $\begin{array}{l}\text { Nests } \\
\text { (range) }\end{array}$ & Roost & Unk \\
\hline \multicolumn{10}{|c|}{ Crater Hill West } \\
\hline \multirow[t]{3}{*}{$\begin{array}{l}\text { RFBO sign } \\
\quad(185-450 \mathrm{~m})\end{array}$} & Visual $[1,2]$ & May 17 & 3 & $N A$ & $N A$ & $N A$ & $\begin{array}{c}1,046 \\
(932-1,168)\end{array}$ & $N A$ & $N A$ \\
\hline & Ground photo $(100 \mathrm{~mm})$ & May 17 & 1 & $\begin{array}{l}0.84-2.03 \mathrm{~cm} / \\
\text { pixel }\end{array}$ & 9 & 2,483 & 1,566 & 400 & 517 \\
\hline & Ground photo $(300 \mathrm{~mm})[3]$ & May 17 & 1 & $\begin{array}{l}0.28-0.68 \mathrm{~cm} / \\
\text { pixel }\end{array}$ & 65 & 3,012 & 2,118 & 543 & 351 \\
\hline $\begin{array}{l}\text { Aerial } \\
\qquad(200-500 \mathrm{~m})\end{array}$ & Aerial photo $(135 \mathrm{~mm})$ [4] & May 13 & 1 & $\begin{array}{l}0.61-1.53 \mathrm{~cm} / \\
\text { pixel }\end{array}$ & 128 & 4,073 & 2,787 & 1,046 & 240 \\
\hline \multicolumn{10}{|c|}{ Crater Hill Interior } \\
\hline \multirow{2}{*}{$\begin{array}{l}\text { Lower } \\
\quad \text { Overlook } \\
\quad(70-600 \mathrm{~m})\end{array}$} & Visual $[1,2]$ & May 16 & 1 & NA & $N A$ & $N A$ & 543 & $N A$ & $N A$ \\
\hline & $\begin{array}{l}\text { Ground photo }(100-400 \mathrm{~mm}) \\
\text { [3] }\end{array}$ & May 17 & 1 & $\begin{array}{l}0.32-0.67 \mathrm{~cm} / \\
\text { pixel }\end{array}$ & 19 & 731 & 472 & 129 & 130 \\
\hline $\begin{array}{l}\text { Aerial } \\
\quad(200-500 \mathrm{~m})\end{array}$ & Aerial photo $(135 \mathrm{~mm})[4]$ & May 13 & 1 & $\begin{array}{l}0.61-1.53 \mathrm{~cm} / \\
\text { pixel }\end{array}$ & 129 & 1,337 & 815 & 424 & 98 \\
\hline \multicolumn{10}{|c|}{ Crater Hill East } \\
\hline $\begin{array}{l}\text { Nihoku } \\
\qquad(90-170 \mathrm{~m})\end{array}$ & Visual [1] & May 14 & 5 & $N A$ & $N A$ & $N A$ & $\begin{array}{c}263 \\
(231-320)\end{array}$ & $N A$ & $N A$ \\
\hline \multirow[t]{2}{*}{$\begin{array}{l}\text { Quarry } \\
\qquad(670-800 \mathrm{~m})\end{array}$} & Visual [2] & May 16 & 4 & $N A$ & $N A$ & $N A$ & $\begin{array}{c}567 \\
(548-590)\end{array}$ & $N A$ & $N A$ \\
\hline & Ground photo $(400 \mathrm{~mm})[3]$ & May 14 & 1 & $\begin{array}{l}0.76-0.91 \mathrm{~cm} / \\
\text { pixel }\end{array}$ & 4 & 1,437 & 798 & 257 & 382 \\
\hline $\begin{array}{l}\text { Aerial } \\
\qquad(200-500 \mathrm{~m})\end{array}$ & Aerial photo $(135 \mathrm{~mm})$ [4] & May 13 & 1 & $\begin{array}{l}0.61-1.53 \mathrm{~cm} / \\
\text { pixel }\end{array}$ & 46 & 1,599 & 1,123 & 364 & 112 \\
\hline \multicolumn{7}{|c|}{ Visual (historical) [1] } & \multicolumn{3}{|c|}{$1,852(1,706-2,031)$} \\
\hline \multicolumn{7}{|c|}{ Visual (best) [2] } & \multicolumn{3}{|c|}{$2,156(2,042-2,301)$} \\
\hline \multicolumn{7}{|c|}{ Ground photo [3] } & \multicolumn{3}{|c|}{$4,058(3,388-4,251)$} \\
\hline \multicolumn{7}{|c|}{ Aerial photo [4] } & \multicolumn{3}{|c|}{$5,049(4,725-5,175)$} \\
\hline
\end{tabular}


Additionally, during the late morning on May 13, 2019, we collected oblique aerial photographs from a helicopter flying along the length, and just offshore, of red-footed booby nesting areas at KPNWR. Aerial photographs were taken with a Canon 5DSr camera (51-megapixel full frame) equipped with a Canon electro-focus (EF) ultra-sonic motor (USM) 135-mm telephoto lens (Canon U.S.A, Melville, New York, U.S.), which resulted in pixel resolutions of $0.61-1.53 \mathrm{~cm}$ pixel $^{-1}$. Ground-based and aerial photos were taken with overlap between individual photos in each set so that observers could later ensure locational reference and complete counting without double-counting.

For each subcolony (fig. 9), we identified all nesting, roosting, and flying red-footed boobies in photos using the program DotDotGoose (Ersts, 2019; fig. 10). For the aerial photos and some of the ground-based photos, duplicate sets of photos were taken. We compared the duplicates and chose the set with the best quality photos for counting. For each photo, we evaluated image quality, geographical location of the image, the degree of overlapping areas between images, and other general observations. We used the DotDotGoose interface to individually count and label each red-footed booby with one of four classifications based on its appearance and behavior at the time the image was captured: "flying," "nesting," "roosting," "unknown." If a nest was not clearly visible, the body alignment of a sitting bird with horizontal posture was used to indicate the presence of a nest (fig. 10). We classified red-footed booby adults sitting with tails down, chest out, and an extended body with no visible nest as "roosting." If a red-footed booby was present, but showed no definitive roosting or nesting cues, or if it was displaying cues of both roosting and nesting behaviors, we classified it as "unknown." Once we counted and categorized each individual, we summed the total number of birds in each class based on their behaviors. When other bird species were spotted in a photo, they were marked, but we did not classify behavior. We avoided double-counting individual birds seen in more than one image by identifying areas of overlap among sequential photos. As we counted through the photo sets, we took note for reference of which of the preceding photos overlapped with the current photo being counted.

To estimate a final nest count for each subcolony, we first had to address the birds that were classified as "unknown" (could be either nesting or roosting, but actual behavior unclear). To do so, we calculated the "nest ratio" as the number of nesting birds to the total number of nesting and roosting combined. We then multiplied the count of "unknown" birds by the "nest ratio" to get the estimated number of "unknown" birds thought to be nesting. We added that number to the count of definitive nests to calculate a final nest count with a range from the definitive nest count (minimum) to the definitive nest count plus all "unknowns" (maximum). To test the counter's consistency at identifying overlaps between images and classifying behavior of birds, we randomly recounted 10 percent of the photos from two photo sets: the 100-mm Crater Hill West photo set (one photo recounted) and the 300-mm Crater Hill West photo set (seven photos recounted). Each photo was cross-referenced with prior photos to determine overlap, and the original classes were used to categorize birds. The recounts were then compared with the original counts.

\section{Results}

\section{Visual Counts and Historical Comparison}

In May 2019, using historical vantage points from 2004 to 2008 , we visually counted an average 1,852 red-footed booby nests (range 1,706-2,031) at KPNWR, including 1,046 $(n=3$, range $932-1,168), 543(n=1)$, and $263(n=5$, range 231-320) nests in the Crater Hill West, Interior, and East subcolonies, respectively (table 11; fig. 11). Replacing the historically surveyed vantage point near the Nihoku fence with the more distant (but less-obstructed) Quarry viewpoint for the Crater Hill East subcolony resulted in an increased average count of 567 nests $(n=4$, range 548-590), which was approximately twice the abundance compared with counts from the Nihoku viewpoint. Substituting the Quarry viewpoint in place of the Nihoku viewpoint, we visually counted an average of 2,156 nests (range 2,042-2,301; table 11) at KPNWR. Based on a sample of 135 random nests at Crater Hill West, 11-percent contained small chicks, all attended by adults, and the remainder were assumed to be incubating or brooding newly hatched chicks that were not viewable (table 12).

\section{Photo Counts}

Using ground-based photos, we counted 2,118, 472, and 798 red-footed booby nests in the Crater Hill West, Interior, and East subcolonies, respectively, and adjusted using proportional classification for individuals classified as "unknown," we estimated a total of 4,058 nests (range $3,388-4,251$ ) for the entire refuge (table 11). Using aerial photos, we counted 2,787, 815, and 1,123 nests at the West, Interior, and East subcolonies respectively, and adjusted using proportional classification, we estimated a total of 5,049 nests (range 4,725-5,175) for the entire refuge (table 11). Original counts and recounts of 10 percent of ground photos from Crater Hill West were similar; recounts showed only 3-percent fewer red-footed booby objects identified (731 original, 709 recount), and similar percentages classified as nesting birds (56.1-percent original, 54.9-percent recount; table 13). 
A.

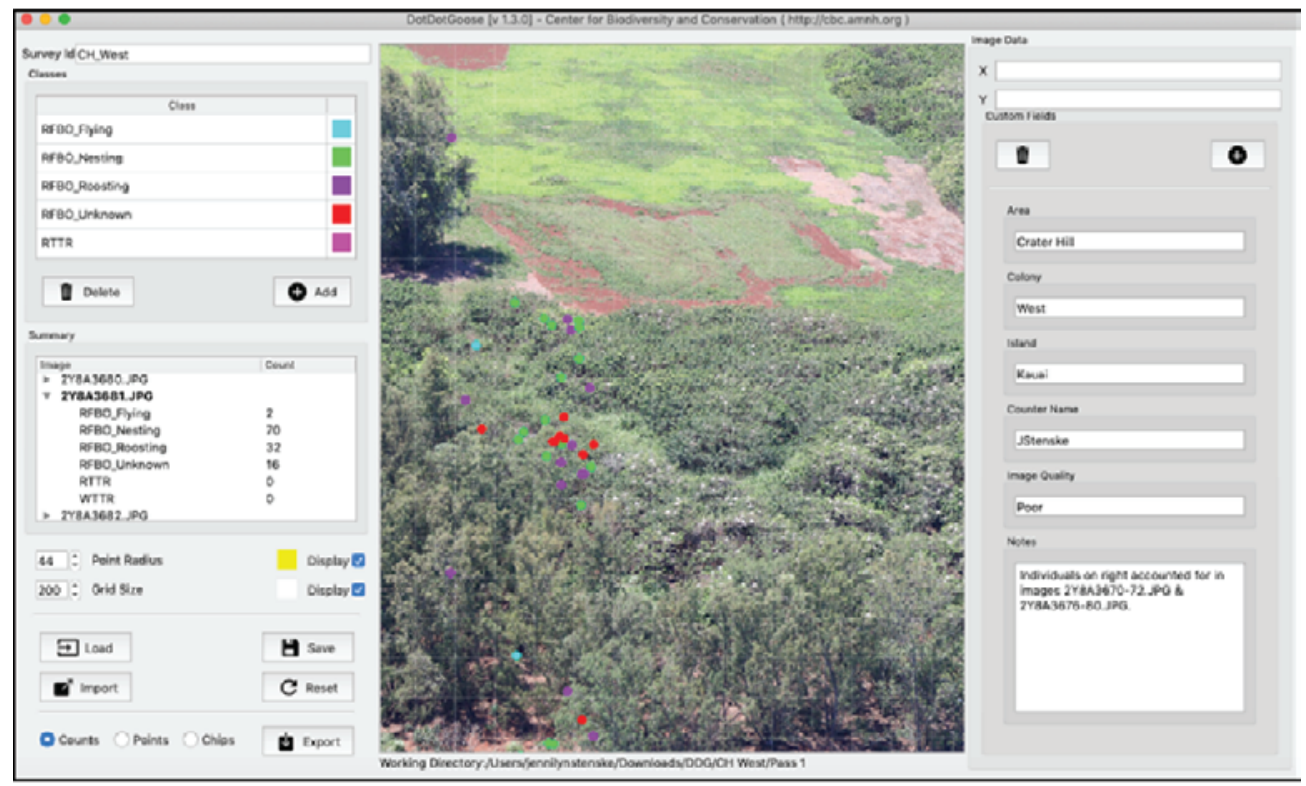

B.

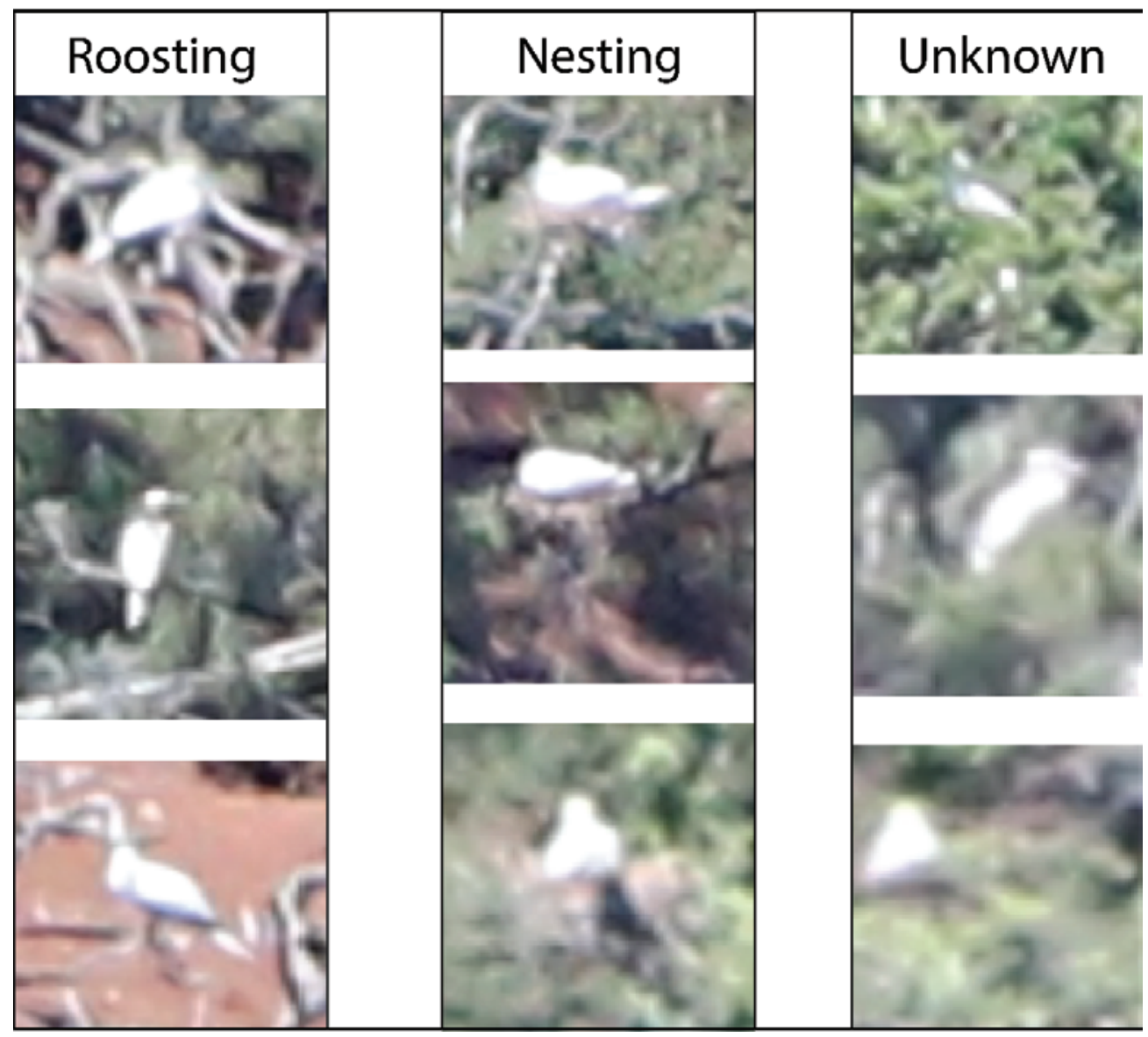

Figure 10. A, Interface of DotDotGoose. Left panel shows behavioral codes, their associated colors, and counts of individuals within the image. Center panel shows the image being examined. Colored dots mark where individuals are, and their behavior, if applicable. Right panel shows the classifications specific to the image being examined. $B$, Excerpts from the image in $A$ showing examples of nesting, roosting, or unknown red-footed booby images. 


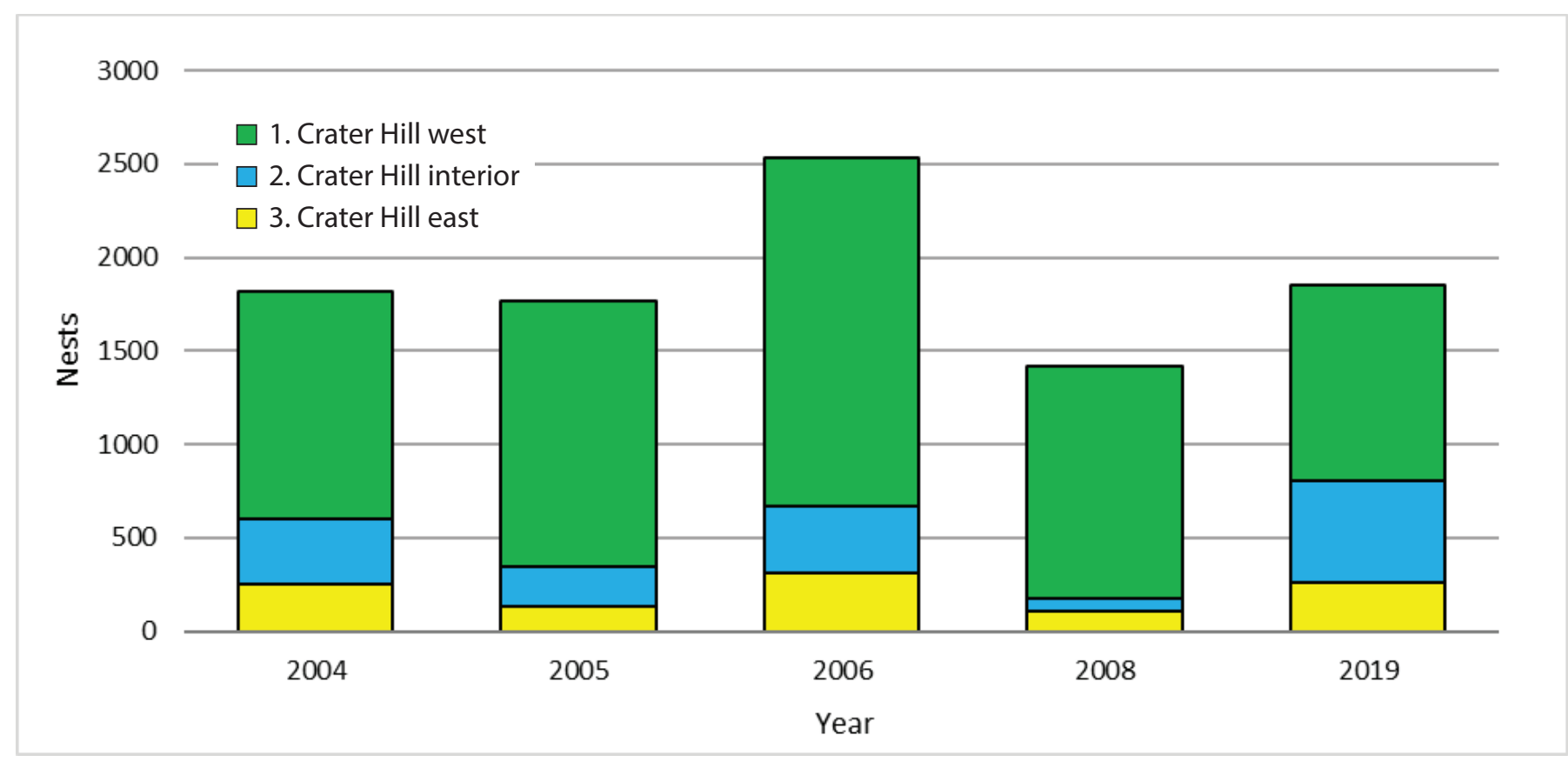

Figure 11. Summary of visual nest counts of red-footed boobies (Sula sula) at Kīlauea Point National Wildlife Refuge, Kaua'i, 2004-2019, using historical viewpoints, broken up by subcolony (fig. 9).

Table 12. Current and historical visual nest counts (U.S. Fish and Wildlife Service, unpub. data, 2019) for red-footed boobies (Sula sula) at Kīlauea Point National Wildlife Refuge, Kaua‘i.

[Counts were conducted from same vantage points for interannual comparisons (RFBO sign for Crater Hill West, Lower Overlook for Crater Hill Interior, and Nihoku for Crater Hill East; figure 9; table 11). Abbreviations: <, less than; , approximately; \%, percent]

\begin{tabular}{lcccccc}
\hline \multirow{2}{*}{ Year } & $\begin{array}{c}\text { Survey } \\
\text { date }\end{array}$ & $\begin{array}{c}\text { Crater } \\
\text { Hill } \\
\text { West }\end{array}$ & $\begin{array}{c}\text { Crater } \\
\text { Hill } \\
\text { Interior }\end{array}$ & $\begin{array}{c}\text { Crater } \\
\text { Hill } \\
\text { East }\end{array}$ & Total & \\
\hline 2004 & May 07 & 1,214 & 350 & 250 & 1,814 & $\begin{array}{c}\text { Most eggs hatched. Chicks }<3-6 \text { weeks old with brooding adults. Only two } \\
\text { chicks unattended, age } ~ 6-8 \text { weeks. }\end{array}$ \\
\hline 2005 & May 18 & 1,422 & 209 & 133 & 1,764 & Most eggs hatched. Nearly half of chicks unattended. \\
\hline 2006 & May 24 & 1,866 & 360 & 310 & 2,536 & Most eggs hatched. One-third of chicks unattended. \\
\hline 2008 & May 22 & 1,243 & 65 & 107 & 1,415 & Most eggs hatched. One-third of chicks unattended. \\
\hline 2019 & May 14-17 & 1,046 & 543 & 263 & 1,852 & $\begin{array}{c}11 \% \text { of random sample of 135 nests on Crater Hill West had small chicks, all } \\
\text { attended by adults. Remainder presumed to be incubating or brooding newly } \\
\text { hatched chicks that were not visible. }\end{array}$ \\
\hline
\end{tabular}


Table 13. Recount results of red-footed boobies (Sula sula) from ground photographs taken in May 2019 at the Crater Hill West subcolony, Kīlauea Point National Wildlife Refuge, Kaua'i.

[The counts and percents of each classification (nesting, roosting, and unknown) are presented for each photo set for its original count and its recount. See table 11 for more information on counting vantages and photo details. Abbreviations: mm, millimeter; \%, percent]

\begin{tabular}{|c|c|c|c|c|c|c|c|c|c|c|c|c|}
\hline \multirow{3}{*}{ Classification } & \multicolumn{4}{|c|}{$\begin{array}{c}\text { Crater Hill West } \\
\text { (seven photos, } 300 \text { mm) }\end{array}$} & \multicolumn{4}{|c|}{$\begin{array}{c}\text { Crater Hill West } \\
\text { (one photo, } 100 \text { mm) }\end{array}$} & \multicolumn{4}{|c|}{$\begin{array}{c}\text { Total } \\
\text { (eight photos) }\end{array}$} \\
\hline & \multicolumn{2}{|c|}{ Original } & \multicolumn{2}{|c|}{ Recount } & \multicolumn{2}{|c|}{ Original } & \multicolumn{2}{|c|}{ Recount } & \multicolumn{2}{|c|}{ Original } & \multicolumn{2}{|c|}{ Recount } \\
\hline & Count & $\%$ & Count & $\%$ & Count & $\%$ & Count & $\%$ & Count & $\%$ & Count & $\%$ \\
\hline Nesting & 179 & 49.2 & 190 & 55.6 & 231 & 62.9 & 199 & 54.2 & 410 & 56.1 & 389 & 54.9 \\
\hline Roosting & 98 & 26.9 & 107 & 31.3 & 65 & 17.7 & 92 & 25.1 & 163 & 22.3 & 199 & 28.1 \\
\hline Unknown & 87 & 23.9 & 45 & 13.2 & 71 & 19.3 & 76 & 20.7 & 158 & 21.6 & 121 & 17.1 \\
\hline Total & 364 & & 342 & & 367 & & 367 & & 731 & & 709 & \\
\hline
\end{tabular}

In most cases, we identified more nests in ground photo counts than visual counts (table 11). The only exception was at Crater Hill Interior, where the visual count (543 nests) was slightly greater than the photo count (472 nests; table 11). Aerial photos consistently revealed more red-footed booby objects (birds and nests) than ground photos, and more nests than visual counts (table 11). The percentage of "unknown" classifications was 11.7-26.6 percent for ground photos and 5.9-7.3 percent for aerial photos. The 300-mm-focal-length ground photos taken at Crater Hill West revealed 529 more red-footed booby objects ( 3,012 total) than the 100 -mm-focal-length photos (2,483 total objects), and 9.1-percent fewer "unknown" classifications (20.8 percent versus 11.7 percent; table 11).

\section{Discussion}

The total visual count of red-footed boobies from historical vantages in May 2019 (1,852 nests, range $1,706-2,031)$ is similar to previous counts $(1,415-2,536$ nests, during 2004-08; table 12; U.S. Fish and Wildlife Service, unpub. data, 2019). We planned our surveys to be done within the same seasonal timeframe (mid-May) as historical counts. Assuming consistency in nest classification and visibility across years, this result indicated no significant change in breeding population of this species between 2004-08 and 2019 (using ground count methods). The visual count of the Crater Hill East subcolony from the new Quarry viewpoint is nearly double that obtained from the historical viewpoint near the Nihoku predator exclusion area. The historical viewpoint is not optimal because nests are underestimated due to viewing angle and are more difficult to classify. Based on limited phenology data from 2004 to 2008 , the 2019 breeding season appeared slightly delayed compared to past years. We found 11 percent of nests containing small chicks attended by adults; whereas, in previous years one-third to one-half of nests contained larger, unattended chicks by mid-May (table 12; U.S. Fish and Wildlife Service, unpub. data, 2019).

Future visual surveys could benefit from (1) the continued use of standardized historical vantages (aside from the Crater Hill East subcolony which we suggest to be counted from the new Quarry viewpoint), (2) an assessment of inter-observer variability in nest classification by having multiple observers count the same colonies from the same vantages, (3) improved consistency across observers and years by training on (2), and (4) continuing to count only breeding birds (nests) because the presence of roosting birds is much more variable based on timing of at-sea foraging trips.

We found that ground photo counts almost always revealed more red-footed booby nests than visual counts from the same vantages. In addition, red-footed booby objects (birds and nests) were identified in greater numbers and with more-definitive classifications using aerial photos compared to ground photos. We suggest that the aerial photo count $(5,049$ nests, range $4,725-5,175)$ represents the best population estimate for nesting red-footed boobies at KPNWR. Neither photo nor visual methods are immune to the subjectivity of observer-based nest classification; however, the photo method presents the observer with more time and tools to methodically count birds and nests, which is the likely reason for increased nest counts using photos compared with visual counts. Additionally, counts from aerial photos likely exceed those of ground photos because the oblique aerial perspective provides a better angle for seeing more nesting habitat at KPNWR, some of which is obscured from the ground vantages. 
Our assessment of the photo counter's ability to consistently identify red-footed booby objects and classify nest status revealed excellent reliability. Photo methods allow for the archival of data and classifications, thus providing a means by which the same or new observers can train on previous data to decrease variability in counts across years. The use of photo methods over time for interannual comparisons requires consistency in photo quality and resolution. By comparing the number and classification of red-footed booby objects between photos shot at 100-mm- and 300-mm-focal-length at Crater Hill West, we were able to determine that photo quality, as measured by effective pixel resolution, has a large impact on the number of objects identified and the definitive classification of those objects. Although the same exact camera and lens need not be used, a combination that provides a similar on-the-ground pixel resolution (based on sensor size/resolution, focal length, and distance to colony) could be employed in the future for ground or aerial photo surveys, and standardized vantages and viewing angles could be maintained.

\section{Summary}

The population counts and estimates for breeding seabirds reported in this study represent the first comprehensive assessments for these species at Kîlauea Point National Wildlife Refuge (KPNWR) in over a decade (red- and white-tailed tropicbirds, red-footed boobies), or ever (wedge-tailed shearwaters). We counted or estimated breeding pair totals of 387 red-tailed tropicbirds, 30 white-tailed tropicbirds, 20,998 wedge-tailed shearwaters, and 5,049 red-footed boobies in the 2019 breeding season. The breeding population size results in this study are greater than those reported in the past (U.S. Fish and Wildlife Service, 2016; U.S. Fish and Wildlife Service, unpub. data, 2019), either because populations have most likely increased (red-tailed tropicbirds) or because new methods were used to comprehensively survey target species (white-tailed tropicbirds, red-footed boobies, wedge-tailed shearwaters). In some cases, the most recent island-wide population estimates for these species on Kaua'i (Pyle and Pyle, 2017) are less than those reported here just for KPNWR, which indicates the need for up-to-date, colony-specific surveys for a better understanding of seabird populations in the main Hawaiian Islands.

Updated counts of breeding seabirds at KPNWR can help inform management decisions within the refuge and throughout the main Hawaiian Islands. Invasive predators (rats, Rattus rattus; cats, Felis catus; dogs, Canis familiaris; barn owls, Tyto alba; pigs, Sus scrofa) all pose large threats to seabirds at KPNWR (U.S. Fish and Wildlife Service, 2016). Kīlauea Point National Wildlife Refuge has an active control program for these invasive predators, and consideration is being given to erecting a dog- and pig-proof fence around the entire refuge (U.S. Fish and Wildlife Service, 2016). Population estimation and monitoring can be used to measure the effectiveness of such management actions (VanderWerf and others, 2014) and the work completed in this study provides an important benchmark from which to do so. Beyond the refuge, potential offshore wind energy development that seeks to minimize climate change effects and provide a source of renewable energy to Hawai' $i$ could threaten these seabird species at sea. For example, white-tailed tropicbirds in the main Hawaiian Islands have been killed in collisions with existing terrestrial wind energy infrastructure (J. Charrier, U.S. Fish and Wildlife Service, unpub. data; 2016); both tropicbird species could be vulnerable to collision with offshore wind energy infrastructure given suspected similarities in flight heights (see Adams and others, 2020, for red-tailed tropicbird flight heights). Sulidae species, such as red-footed boobies, could be susceptible to displacement from preferred at-sea foraging habitat by offshore development (Garthe and others, 2017). Accurate and comprehensive population estimates, when combined with at-sea tracking data of seabirds breeding at KPNWR (Adams and others, 2020), can be used to assess population-level vulnerability to potential negative interactions with offshore wind energy infrastructure (Garthe and others, 2017; Kelsey and others, 2018).

The data reported herein are publicly available and can be accessed in an associated data release (Felis and others, 2020). 


\section{References Cited}

Adams, J., Felis, J.J., and Czapanskiy, M.F., 2020, Habitat affinities and at-sea ranging behaviors among main Hawaiian Island seabirds: Breeding seabird telemetry, 2013-2016: Camarillo, California, U.S. Department of the Interior, Bureau of Ocean Energy Management, Pacific Outer Continental Shelf Region, Bureau of Ocean Energy Management 2020-006, 111 p., https://espis.boem.gov/ final\%20reports/BOEM_2020-006.pdf.

Bureau of Ocean Energy Management, 2020, Hawaii activities: Bureau of Ocean Energy Management, accessed April 28, 2020, at https://www.boem.gov/renewable-energy/ state-activities/hawaii-activities.

Byrd, G.V., and Boynton, D.S., 1979, The distribution and status of wedge-tailed shearwaters on Kaua'i: Elepaio, v. 39, p. 129-131.

Byrd, G.V., and Zeillemaker, C.F., 1981, Seabirds of Kilauea Point, Kauai Island, Hawaii: Elepaio, v. 41, no. 8, p. 67-70.

Byrd, G.V., Moriarty, D.I., and Brady, B.G., 1983, Breeding biology of wedge-tailed shearwaters at Kilauea Point, Hawaii: The Condor, v. 85, no. 3, p. 292-296, https://doi.org/10.2307/1367063.

Catry, P., Clark, T.J., Crofts, S., Stanworth, A., and Wakefield, E.D., 2019, Changes and consistencies in marine and coastal bird numbers on Kidney Island (Falkland Islands) over half a century: Polar Biology, v. 42, no. 11, p. 2171-2176, https://doi.org/10.1007/s00300-019-02587-0.

Citta, J., Reynolds, M.H., and Seavy, N., 2007, Seabird monitoring assessment for Hawai' $i$ and the Pacific Islands-Hawai'i Cooperative Studies Unit Technical Report, HSCU-007: University of Hawai`i at Hilo, 122 p.

Cochran, W.G., 1977, Sampling techniques (3d ed.): John Wiley \& Sons, 428 p.

Dunlop, J.N., Long, P., Stejskal, I., and Surman, C., 2002, Inter-annual variations in breeding participation at four Western Australian colonies of the wedge-tailed shearwater Puffinus pacificus: Marine Ornithology, v. 30, no. 1, p. 13-18.

Dyer, P.K., O'Neill, P., and Hulsman, K., 2005, Breeding numbers and population trends of wedge-tailed shearwater (Puffinus pacificus) and Black Noddy (Anous minutus) in the Capricornia Cays, southern Great Barrier Reef: Emu - Austral Ornithology, v. 105, no. 3, p. 249-257, https://doi.org/10.1071/MU04011.

Ersts, P.J., 2019, DotDotGoose (version 1.1.1): American Museum of Natural History, Center for Biodiversity and Conservation, accessed August 12, 2019, at https://biodiversityinformatics.amnh.org/open_source/ dotdotgoose.
Felis, J.J., Kelsey, E.C., Adams, J., Stenske, J.G., and White, L.M., 2020, Population estimates for selected breeding seabirds at Kîlauea Point National Wildlife Refuge, Kaua 'i, in 2019 : U.S. Geological Survey data release, https://doi.org/10.5066/P93MPDR1.

Fleet, R.R., 1972, Nesting success of the red-tailed tropicbird on Kure Atoll: The Auk, v. 89, no. 3, p. 651-659, https://doi.org/10.1093/auk/89.3.651.

Frederick, P.C., Hylton, B., Heath, J.A., and Ruane, M., 2003, Accuracy and variation in estimates of large numbers of birds by individual observers using an aerial survey simulator: Journal of Field Ornithology, v. 74, no. 3, p. 281-287, https://doi.org/10.1648/0273-8570-74.3.281.

Garkaklis, M.J., Sims, C.V., Bradley, J.S., and Wooller, R.D., 1998, The breeding phenology of wedge-tailed shearwaters Puffinus pacificus on Rottnest Island, Western Australia: Emu - Austral Ornithology, v. 98, no. 4, p. 317-319, https://doi.org/10.1071/MU98043.

Garthe, S., Markones, N., and Corman, A.M., 2017, Possible impacts of offshore wind farms on seabirds - A pilot study in Northern Gannets in the southern North Sea: Journal of Ornithology, v. 158, no. 1, p. 345-349, https://doi.org/10.1007/s10336-016-1402-y.

Goodman, L.A., 1960, On the exact variance of products: Journal of the American Statistical Association, v. 55, no. 292, p. 708-713, https://doi.org/10.1080/01621459.1960.10483369.

Harrison, C.S., 1990, Seabirds of Hawaii-Natural history and conservation: Ithaca, NY, Cornell University Press, 288 p.

Hatfield, J.S., Reynolds, M.H., Seavy, N.E., and Krause, C.M., 2012, Population dynamics of Hawaiian seabird colonies vulnerable to sea-level rise: Conservation Biology, v. 26, no. 4, p. 667-678, https://doi.org/10.1111/j.1523-1739.2012.01853.x.

Hijmans, R.J., 2019, Raster-Geographic data analysis and modeling: $\mathrm{R}$ package version 3.0-7, https://CRAN.R-project.org/package=raster.

International Union for Conservation of Nature, 2020, The IUCN red list of threatened species (version 2020-1): International Union for Conservation of Nature, accessed March 19, 2020, at https://www.iucnredlist.org.

Kelsey, E.C., Felis, J.J., Czapanskiy, M., Pereksta, D.M., and Adams, J., 2018, Collision and displacement vulnerability to offshore wind energy infrastructure among marine birds of the Pacific Outer Continental Shelf: Journal of Environmental Management, v. 227, p. 229-247, https://doi.org/10.1016/j.jenvman.2018.08.051. 
Learned, J., Smith, S., and Penniman, J., 2020, Red-footed boobies on Maui-First breeding account and implications for seabird habitat protection on high Hawaiian Islands, in Pacific Seabird Group, 2020 Pacific Seabird Group 47th annual meeting - Book of abstracts: Pacific Seabird Group Meeting, February 14, 2020, p. 44-45, https://pacificseabirdgroup.org/wp-content/uploads/2020/ 05/PSG2020_Abstracts.pdf.

Lee, D.S., and Walsh-McGee, M., 2020, White-tailed tropicbird (Phaethon lepturus), version 1.0, in Billerman, S.M., ed., Birds of the World: Ithaca, NY, USA, Cornell Lab of Ornithology, https://doi.org/10.2173/bow.whttro.01.

Pebesma, E.J., and Bivand, R.S., 2005, Classes and methods for spatial data in R: R News, v. 5, no. 2, p. 9-13.

Pravder, H., Prestridge, C., and Hyrenbach, K.D., 2015, Wedge-tailed shearwater breeding phenology at the Freeman seabird preserve, O'ahu, Hawai'i: Elepaio, v. 75, no. 3, p. 17-21.

Pyle, R.L., and Pyle, P., 2017, The birds of the Hawaiian Islands-Occurrence, history, distribution, and status (version 2): Honolulu, HI, U.S.A., B.P. Bishop Museum, http://hbs.bishopmuseum.org/birds/rlp-monograph.

R Core Team, 2013, R-A language and environment for statistical computing: Vienna, Austria, R Foundation for Statistical Computing, http://www.R-project.org/.

Raine, A.F., Rothe, J., and Driskell, S., 2020, An updated avifauna of Moku'ae'ae Rock Islet 2019: Technical Report 202, University of Hawai'i at Mānoa, Honolulu, Hawai' i.

Reynolds, M.H., Courtot, K.N., Berkowitz, P., Storlazzi, C.D., Moore, J., and Flint, E., 2015, Will the effects of sea-level rise create ecological traps for Pacific island seabirds?: PLoS One, v. 10, no. 9, 23 p., https://doi.org/10.1371/journal.pone.0136773.

Richardson, F., and Bowles, J., 1964, A survey of the birds of Kauai Hawaii-Honolulu, Hawaii, B.P: Bishop Museum Bulletin, v. 227, p. 1-49.

Russell, T.A., and VanderWerf, E.A., 2010, Red-footed booby Sula breeding success at Ulupa'u Crater, Marine Corps Base Hawaii: Marine Ornithology, v. 38, no. 2, p. 129-131.

Schreiber, B.A., and Schreiber, R.W., 2020, Red-tailed tropicbird (Phaethon rubricauda), version 1.0, in Billerman, S.M., ed., Birds of the World: Ithaca, NY, USA, Cornell Lab of Ornithology, https://doi.org/10.2173/bow.rettro.01.

Schreiber, E.A., Schreiber, R.W., and Schenk, G.A., 2020, Red-footed booby (Sula sula), version 1.0, in Billerman, S.M., ed., Birds of the World: Ithaca, NY, USA, Cornell Lab of Ornithology, https://doi.org/10.2173/bow.refboo.01.
State of Hawaii, 2020, Hawaii clean energy initiative: The State of Hawaii, accessed April 24, 2020, at http://www.hawaiicleanenergyinitiative.org/.

Tyler, W.B., 1991, A tropical seabird nesting at a temperate latitude-The ecology of red-tailed tropicbirds (Phaethon rubricauda) at Midway Atoll: Santa Cruz, University of California.

U.S. Fish and Wildlife Service, 2016, Kīlauea Point National Wildlife Refuge comprehensive conservation plan: Kīlauea, Hawaii, and Portland, Oregon, U.S. Fish and Wildlife Service, 574 p., https://www.fws.gov/uploadedFiles/Region_1/NWRS/ Zone_1/Kauai_Complex/Kilauea_Point/Documents/ Kilauea\%20Point\%20NWR\%20fCCP.pdf.

U.S. Geological Survey, 2013, USGS NED n23w160 1/3 arc-second 20131 x 1 degree ArcGrid: U.S. Geological Survey, https://www.sciencebase.gov/catalog/item/ 581d21dae4b08da350d53be2.

VanderWerf, E.A., and Young, L.C., 2014, Breeding biology of red-tailed tropicbirds (Phaethon rubricauda) and response to predator control on $\mathrm{O}^{\text {' }} \mathrm{ahu}$, Hawai' $\mathrm{i}$ : Marine Ornithology, v. 42, no. 1, p. 73-76.

VanderWerf, E.A., Wood, K.R., Swenson, C., LeGrande, M., Eijzenga, H., and Walker, R.L., 2007, Avifauna of Lehua Islet, Hawai' $i$ - Conservation value and management needs: Pacific Science, v. 61, no. 1, p. 39-52, https://doi.org/10.1353/psc.2007.0012.

VanderWerf, E.A., Young, L.C., Crow, S.E., Opie, E., Yamazaki, H., Miller, C.J., Anderson, D.G., Brown, L.S., Smith, D.G., and Eijzenga, J., 2014, Increase in wedge-tailed shearwaters and changes in soil nutrients following removal of alien mammalian predators and nitrogen-fixing plants at Kaena Point, Hawaii: Restoration Ecology, v. 22, no. 5, p. 676-684, https://doi.org/10.1111/rec.12126.

Whittow, G.C., 2020, Wedge-tailed shearwater (Ardenna pacifica), version 1.0, in Billerman, S.M., ed., Birds of the World: Ithaca, NY, USA, Cornell Lab of Ornithology, https://doi.org/10.2173/bow.wetshe.01.

Young, L.C., Behnke, J.H., VanderWerf, E.A., Raine, A.F., Mitchell, C., Kohley, C.R., Dalton, M., Mitchell, M., Tonneson, H., DeMotta, M., Wallace, G., Nevins, H., Hall, C.S., and Uyehara, K., 2018, The Nihoku ecosystem restoration project-A case study in predator exclusion fencing, ecosystem restoration, and seabird translocation: Honolulu, Hawaii, Pacific Cooperative Studies Unit Technical Report 198, University of Hawai'i at Mānoa, Department of Botany, $83 \mathrm{p}$. 
32 Population Estimates for Selected Breeding Seabirds at Kīlauea Point National Wildlife Refuge, Kaua'i, in 2019

\section{Appendix 1.}

Table 1.1. Locations of vantages used for species counts as described in the text.

\begin{tabular}{llcc}
\hline \multicolumn{1}{c}{ Location name } & \multicolumn{1}{c}{ Species } & Latitude & \multicolumn{1}{c}{ Longitude } \\
\hline Lighthouse viewpoint & Red-tailed tropicbird & 22.231657 & -159.401970 \\
Red-footed booby sign & Red-footed booby & 22.230260 & -159.401991 \\
Crater Hill lower overlook & Red-tailed tropicbird, Red-footed booby & 22.227166 & -159.397403 \\
Crater Hill upper overlook & Red-tailed tropicbird & 22.223520 & -159.395362 \\
Crater Hill east viewpoint & Red-tailed tropicbird & 22.223042 & -159.393976 \\
Nihoku viewpoint & Red-footed booby & 22.222593 & -159.391014 \\
Mokolea/Quarry viewpoint & Red-tailed tropicbird, Red-footed booby & 22.222002 & -159.385184 \\
\hline
\end{tabular}


For more information concerning the research in this report, contact the

Director, Western Ecological Research Center

U.S. Geological Survey

3020 State University Drive East

Sacramento, California 95819

https://www.usgs.gov/centers/werc

Publishing support provided by the U.S. Geological Survey

Science Publishing Network, Sacramento Publishing Service Center 


\section{兽}

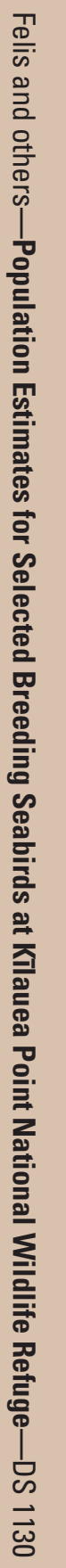

